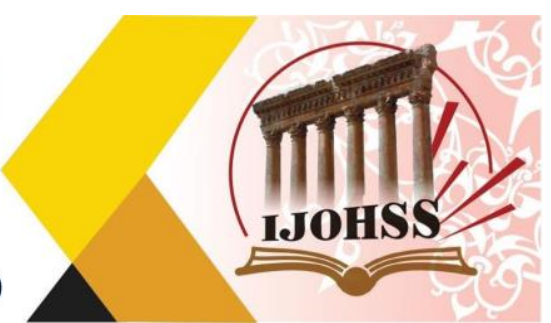

\title{
الوكالة الساترة للبيع في القاتون العراقي والقانون المقارن
}

\author{
م مدئ زينة قدرة لطيف \\ كلية الحقوق و العلوم السياسية

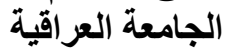 \\ العراق \\ zeena.qudrat@gmail.com
}

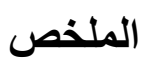

يهدف البحث الحالي إلى الخوض في موضوع الوكالة الساترة للبيع في القانون العر اقي بالمقارنة مع القو انين الأخرى .وقد تمثلت أهداف البحث في الكثف عن ماهية الوكالة الساترة للبيع ، وذلك في كل من القانون العر اقي و القو انين المقارنة.

بحيث تعد الوكالة الساترة للييع لثكل (الوكالة القابلة للعزل) ، و غالباً ما يلجأ الأفراد إليها بغية ستر عقد بيع يتطلب شروطاً قانونية معينة ، و البيع الذي يتم ستره بعقد صوري ليس بييع باطل في حال كان العقد الآخر عقد

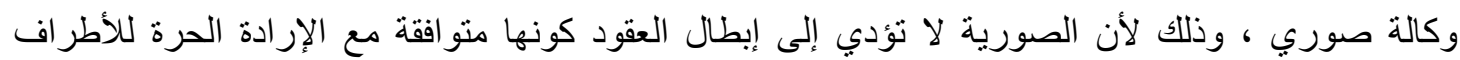

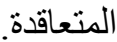
وقد يلجأ الافر اد الى الوكالة الساترة للبيع في الغالب اما بغرض التهرب من دفع الرسوم ،او بغرض ستر عقد التصرف ممنوع التصرف فيه، وأثار المشرع العر اقي للوكالة الساترة للبيع في (المادة 943) من القانون المدني ، وميز بينها وبين الاسم المستعار ،اما القانون المدني المصري، والقانون المدني الأردني ، وكذللك قانون موجبات و العقود اللبناني ، اتفقو ا واختلفو ا في جو انب مع القانون العر اقي حول هذه المسألة . 


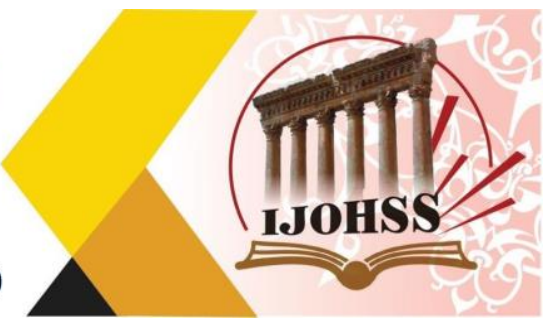

\title{
Covering Agency for Sale in Iraqi and Comparative Law
}

\author{
Dr. Zina Qudrat Latif \\ Faculty of Law and Political Sciences \\ Iraqi University \\ Iraq \\ zeena.qudrat@gmail.com
}

\begin{abstract}
The current research aims to delve into the topic of covert agency for sale in Iraqi law in comparison with other laws. The aims of the research were to reveal what the cover agency for sale is, in both Iraqi law and comparative laws. So that the cover agency for sale is considered to be a form (insulation agency), and individuals often resort to it in order to cover a sales contract that requires certain legal conditions, and the sale that is concealed by a fictitious contract is not invalid in the event of the other contract being a agency agency contract, because the sham does not lead to Contracts are void as compatible with the free will of the contracting parties.

In fact, individuals may resort to the cover agency for sale mostly either for the purpose of evading the payment of fees, or for the purpose of covering the disposal contract forbidden to be disposed of, and the Iraqi legislator indicated to the cover agency for sale in (Article 943) of the Civil Law, and distinguished them from the pseudonym, either the law The Egyptian civil and Jordanian civil law, as well as the Lebanese obligations and contracts law, agreed and disagreed in aspects with Iraqi law on this issue.
\end{abstract}

Keywords: covering agency, Iraqi law, comparative law. 


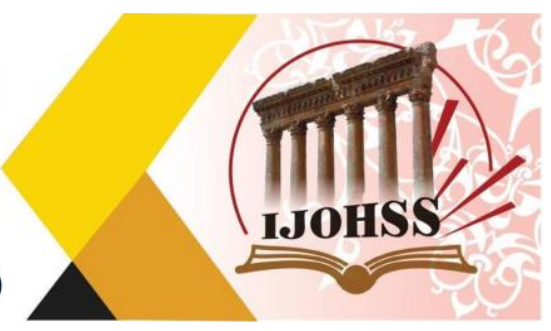

المقدمة

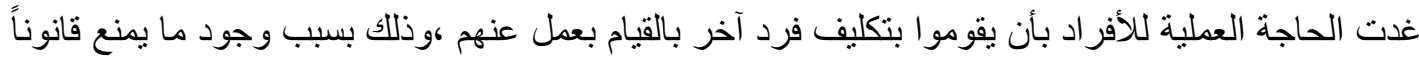

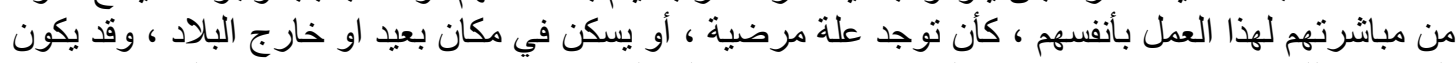

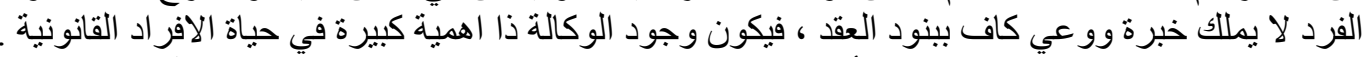

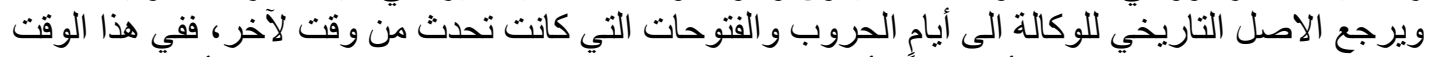

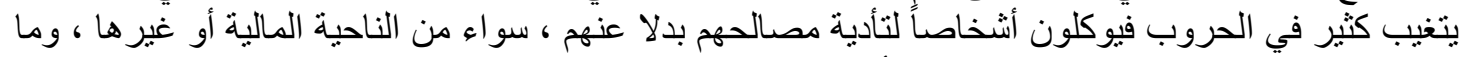

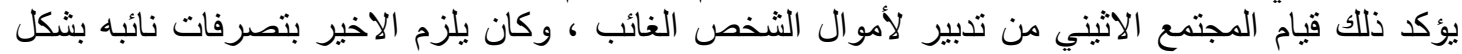

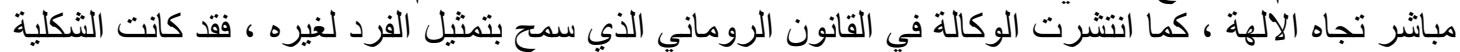

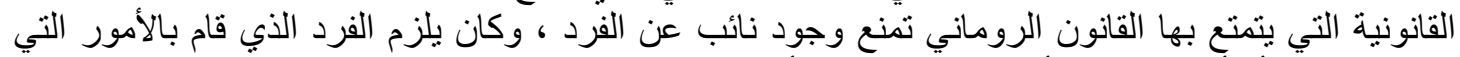

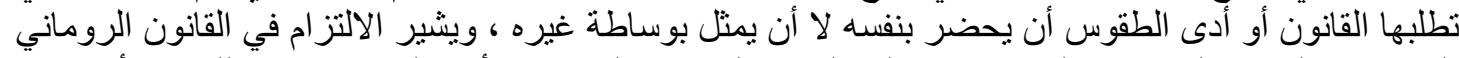

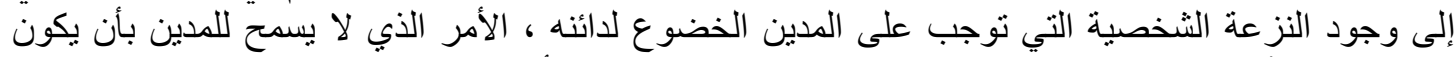

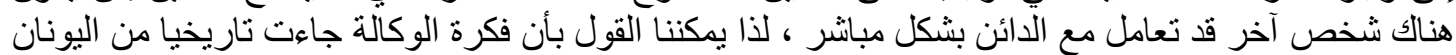

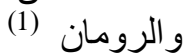

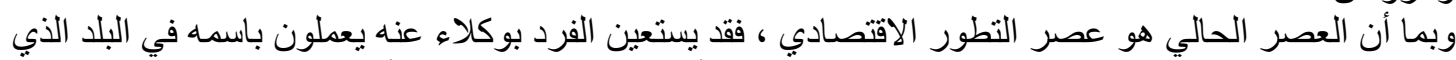

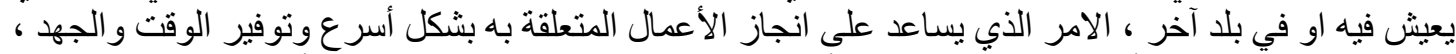

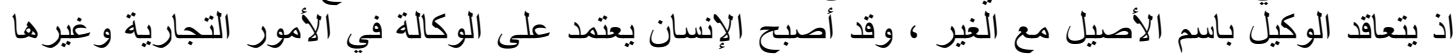

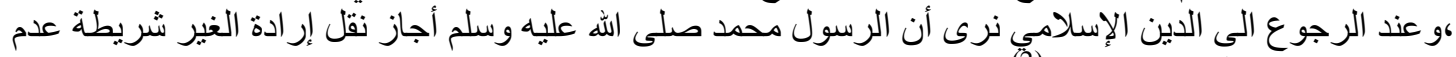

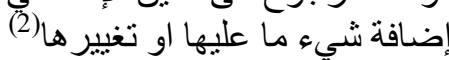
وقد عمدت الباحثه في هذا البحث لاختيار موضوع الوكالة الباتلة الساترة للبيع في القانون العراقي والقانون

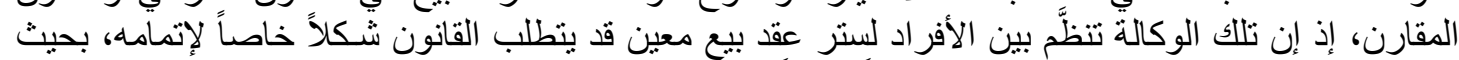

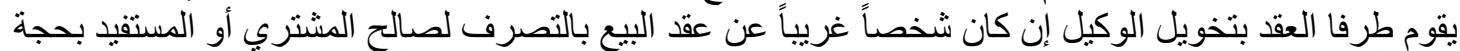

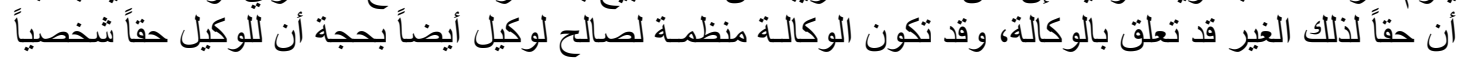
قد تملق بها. إذ تمنح هذه الوكالة الوكيل صلاحيات محددة قد تضيق وقد تتسع بمقدار ما يريد البـائع (الموكل) أن بعطي

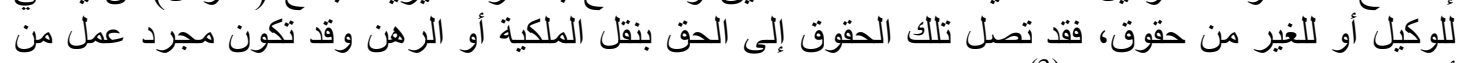

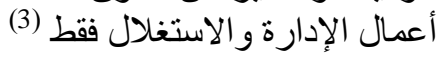

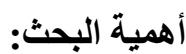

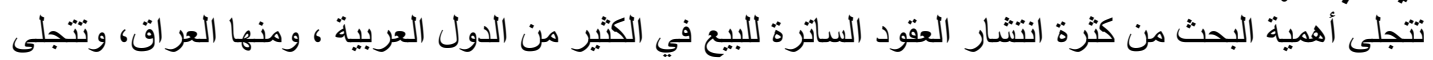

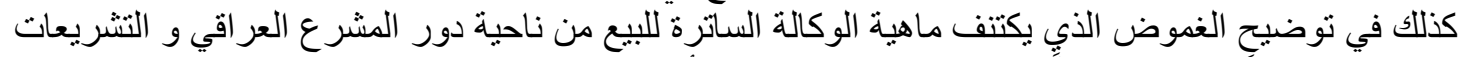

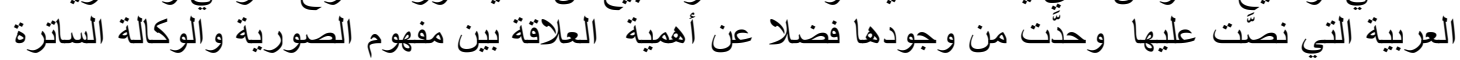

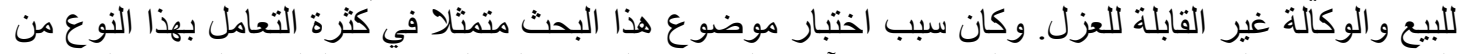

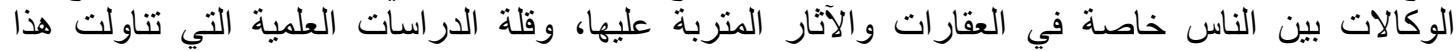

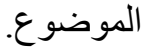

بن (1) هبة بوذر اع ـ النظام القانوني لعقد الوكالة. رسالة ماجستير مقدمة الى كلية الحقوق و العلوم السياسية جامعة العربي

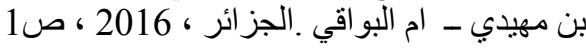

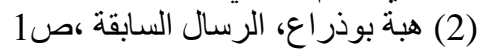

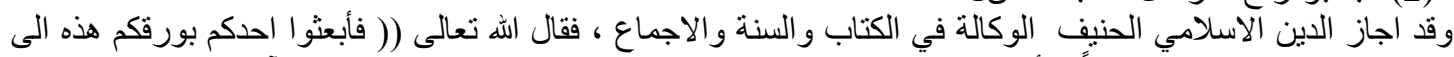

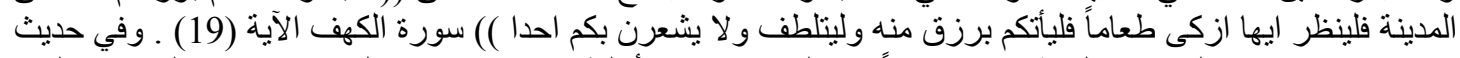

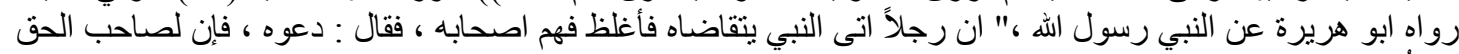

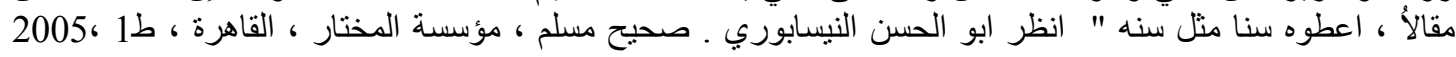

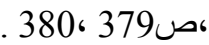
(3) إسحق احمد حمدان علي ،الوكالة الغير قابلة للعزل في التشريع الاردني بحث قانوني مقدم الى كلية الدراسات العليا-

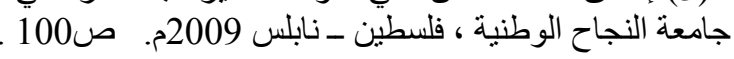


المجلة اللدولية اللملوم الأسانية والإجتاعياة

International Journal of Humanities and Social Sciences

website:www.ijohss.com

Email:editor@ijohss.com

ISSN: $2415-4822$

أغسطس 2020

العدد (14)

Volume (14) August 2020

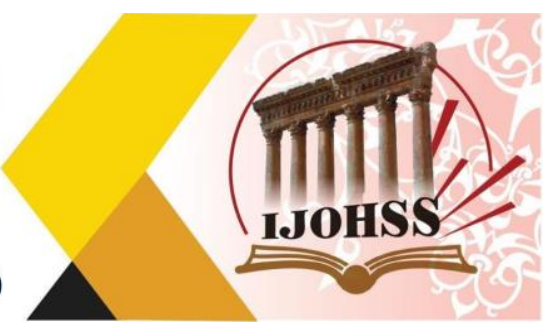

إثكالية البحث

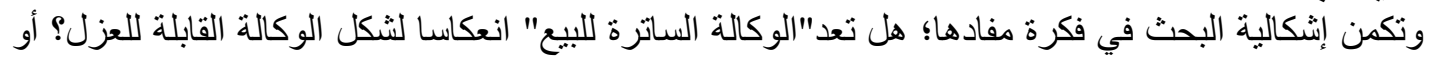

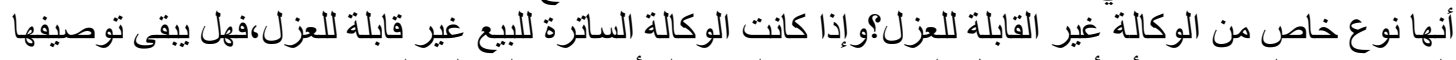

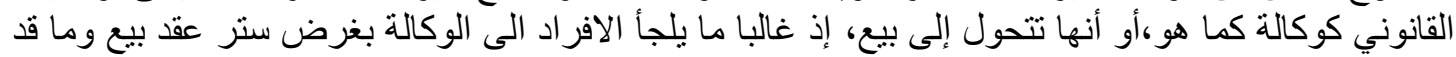

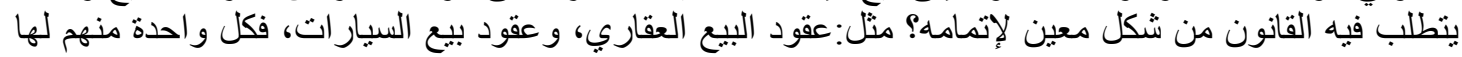

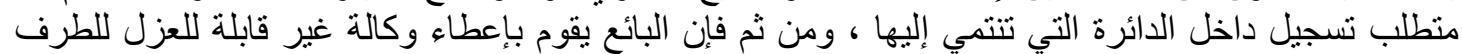

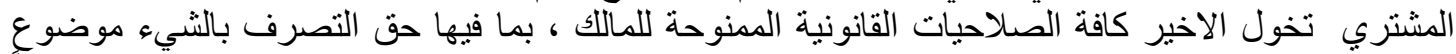

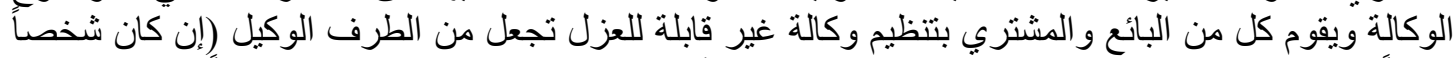

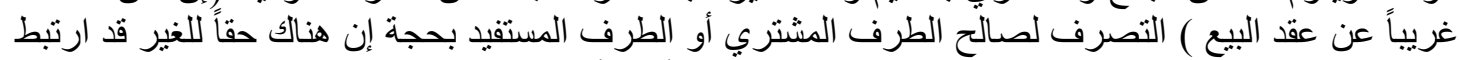

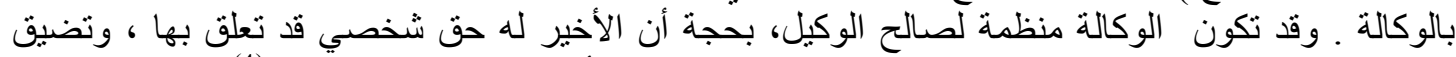

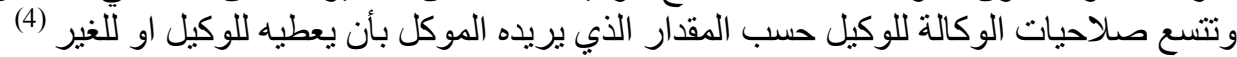

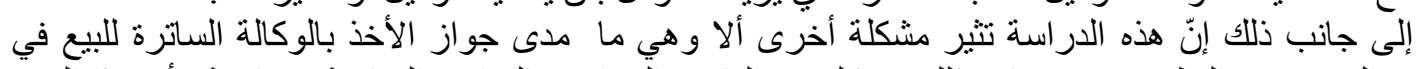

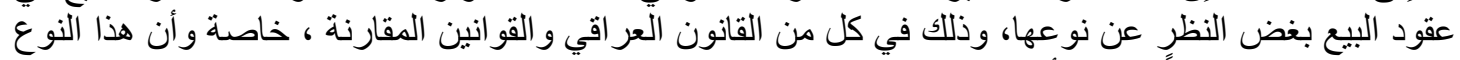

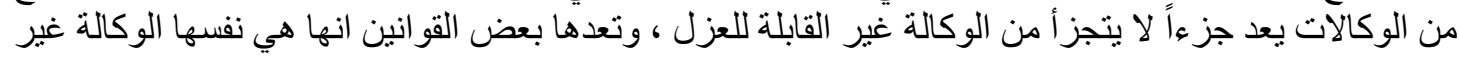

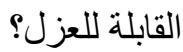

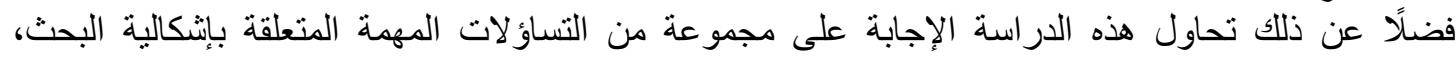

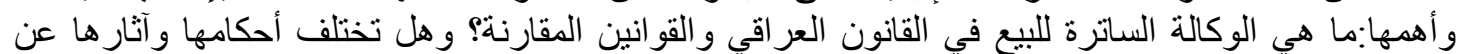

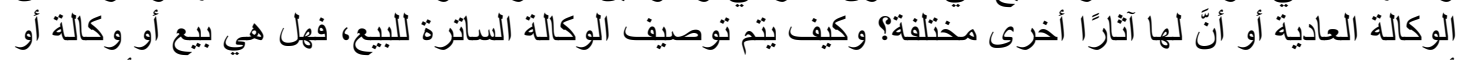

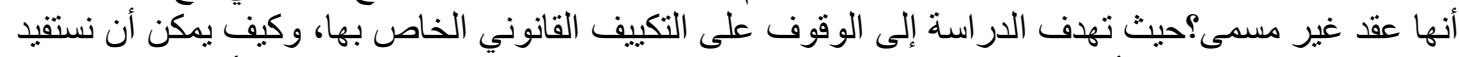

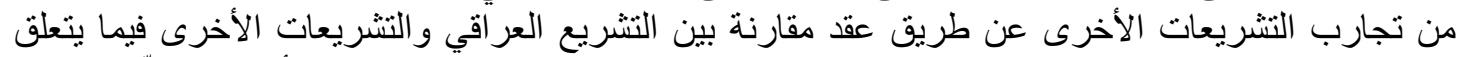

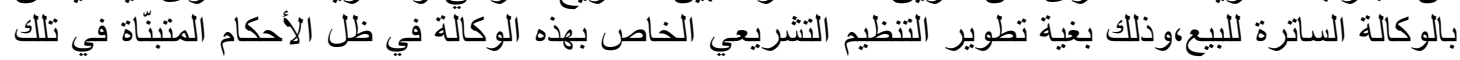

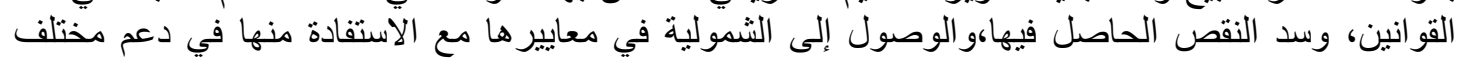

التشريعات.

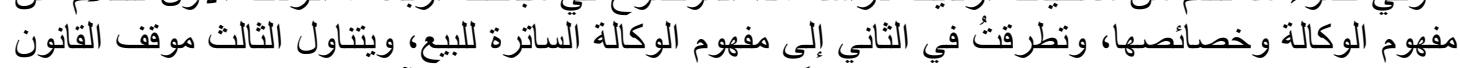

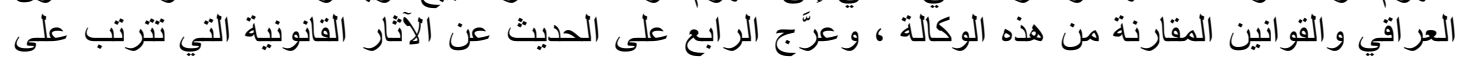

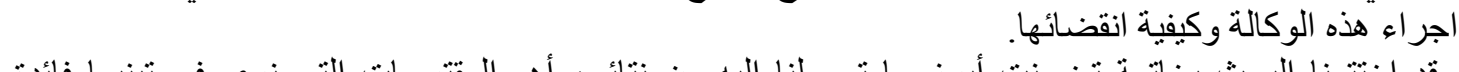
وقد اختتمنا البحث بخاتمة تضمنت أبرز البهن ما توصلنا إليه من نتائج،وأهم المقترحات التي نرى في تبنيها فائدة عمليّة.

\section{المبحث الأول: الوكالة}

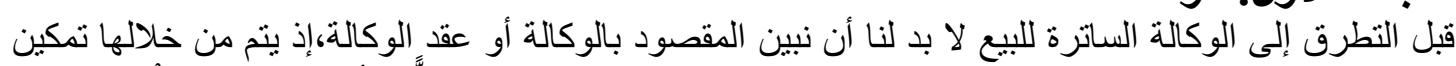

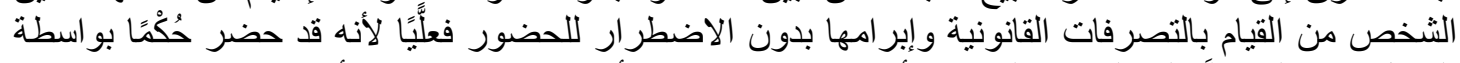

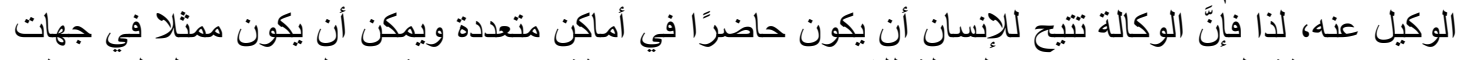

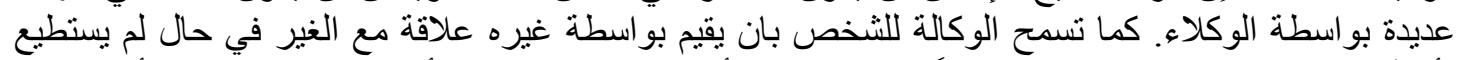

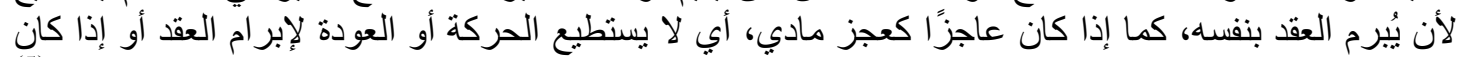

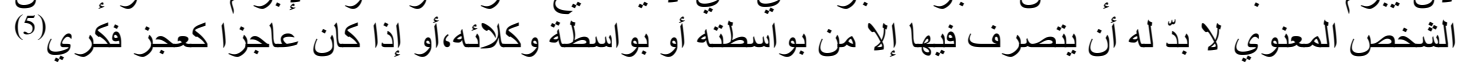

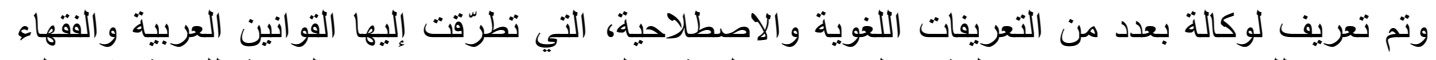

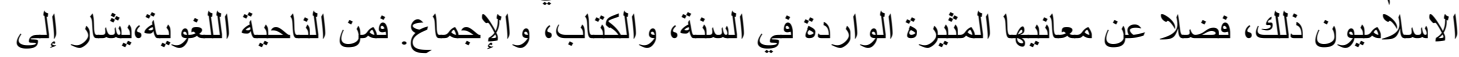

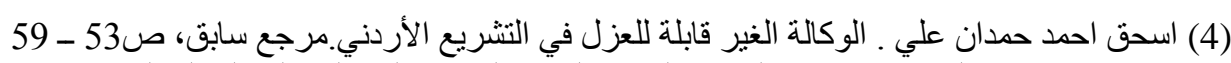

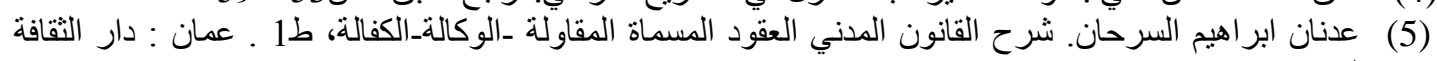

للنشر والتوزيع ، 2009م ـ ص123. 
المجلة الحولية اللعلوم الآنسانية والإمتماعية

International Journal of Humanities and Social Sciences

website:www.ijohss.com

Email:editor@ijohss.com

ISSN: $2415-4822$

العدد (14) أغسطس 2020

Volume (14) August 2020

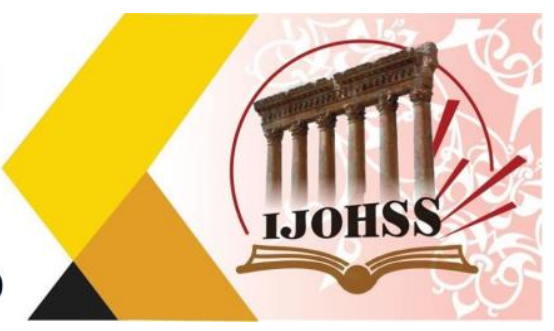

الوكالة أنها الكفالة،حيث قال بن منظور بأنَّ الوكيل هو المقيم الكفيل بأرزاق العباد،ولكنه يقصد في حقيقة الأمر

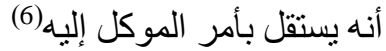

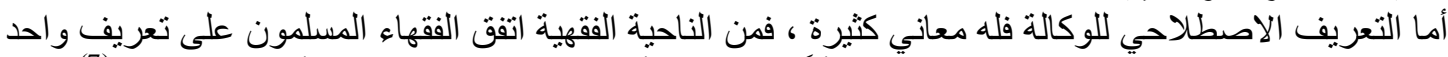

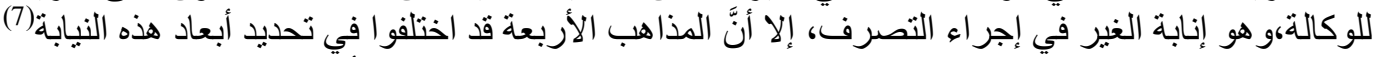

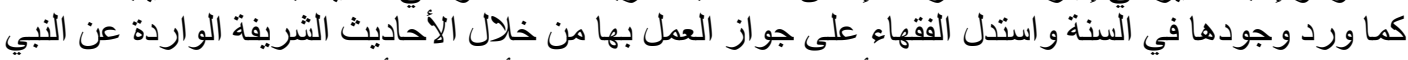

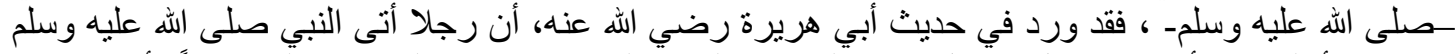

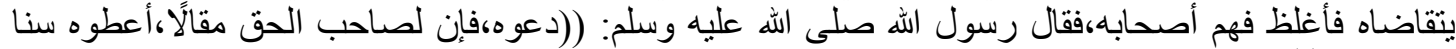

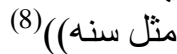
وقد انعقد الإجماع على جواز الوكالة، إذ اتفق الفقهاء على جواز العمل بالوكالة، لأنَّ هذه الحاجة داعية إليها، بما

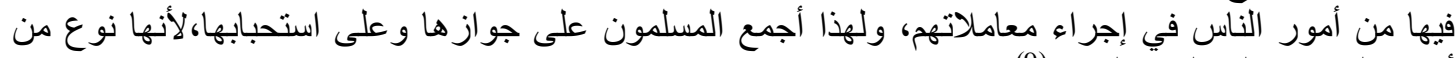

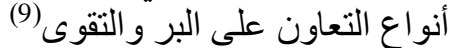

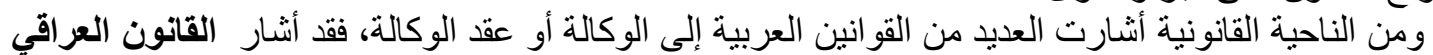

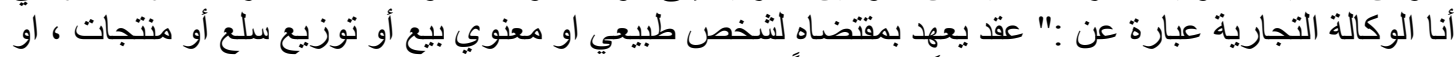

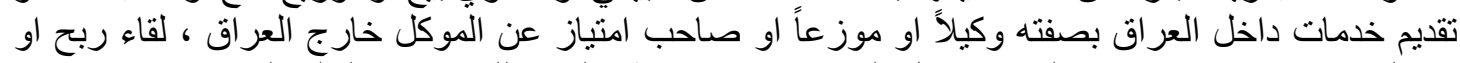

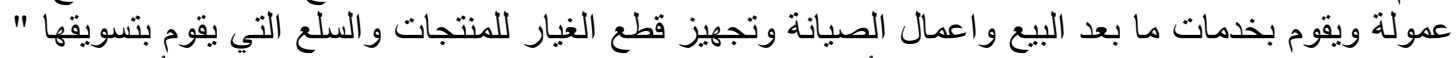

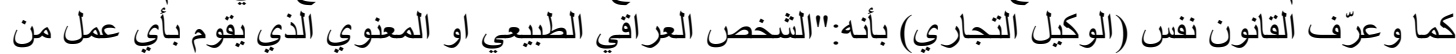

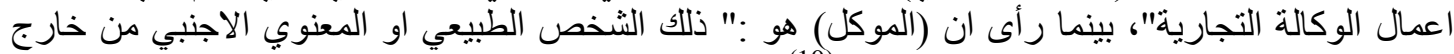

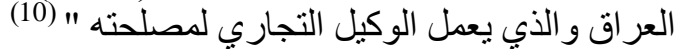

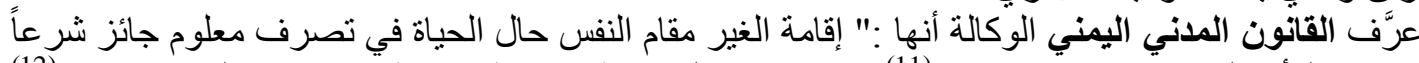

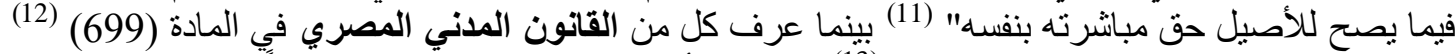

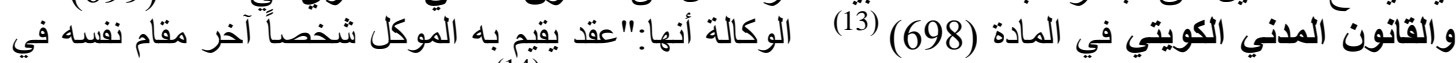

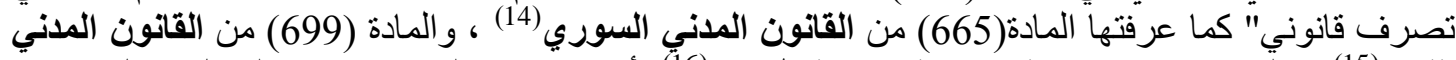

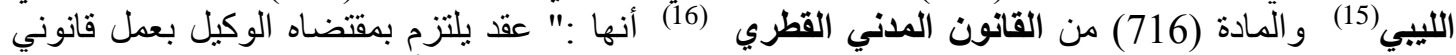

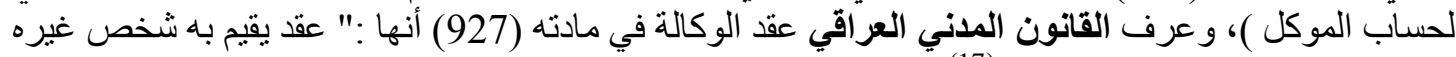

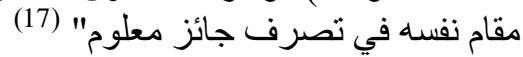

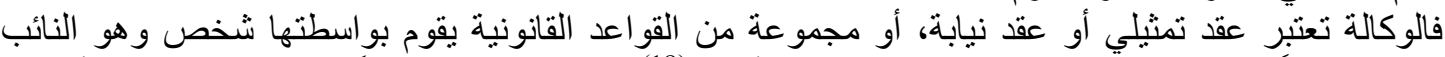

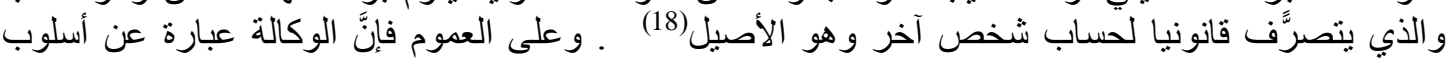

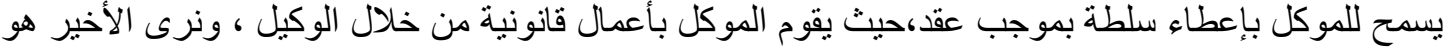

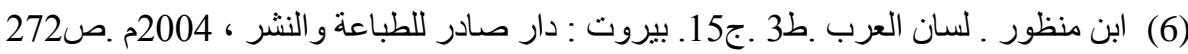

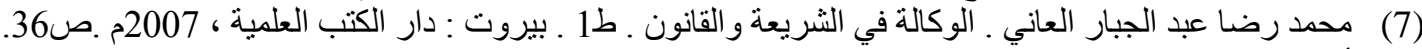

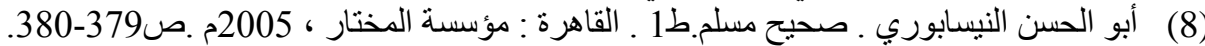

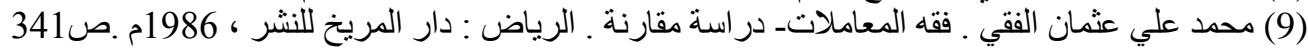

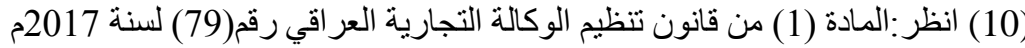

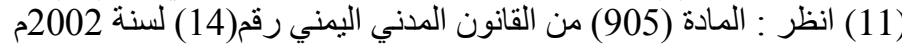

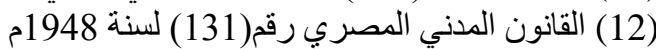

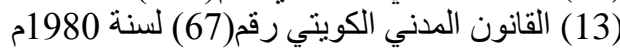

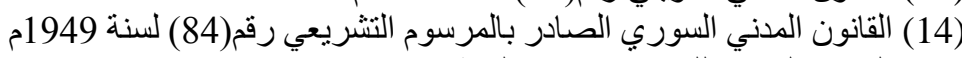

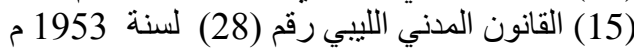

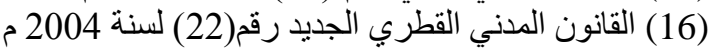

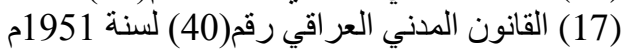

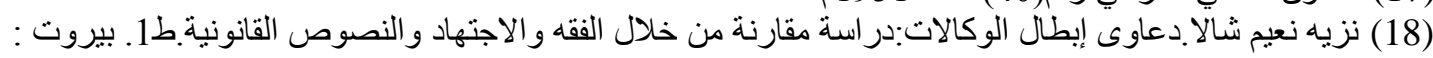

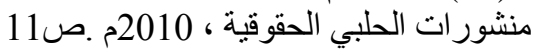


المجلة اللدولية اللملوم الأسانية والإجتاعياة

International Journal of Humanities and Social Sciences

website:www.ijohss.com

Email:editor@ijohss.com

ISSN: $2415-4822$

العدد (14) أغسطس 2020

Volume (14) August 2020

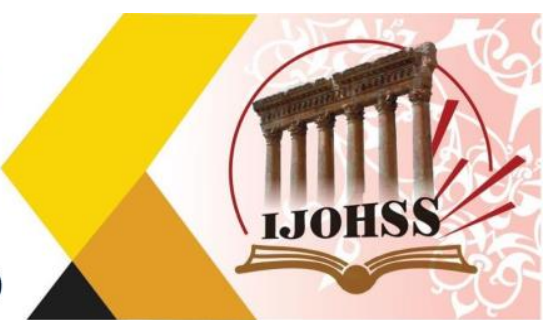

شخص يمثل الطرف الموكل في كافة علاقاته مع الغير ، بغرض البيع أو الشراء أو التأجير أو الدفع أو أعمال إجر ائية (19)

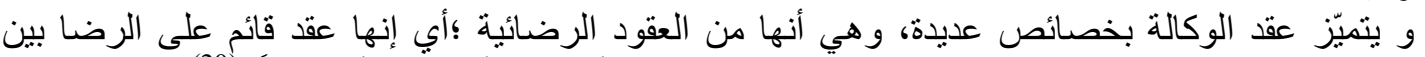

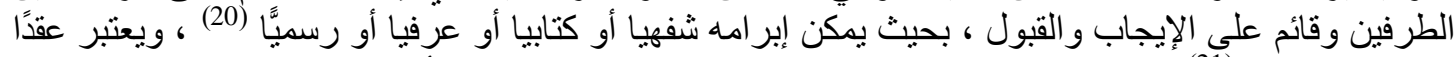

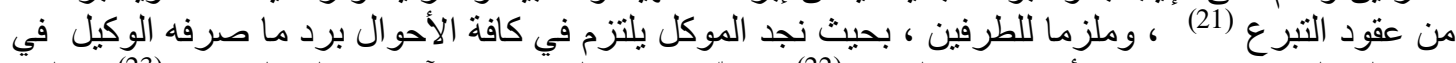

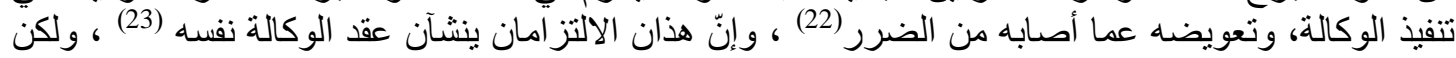

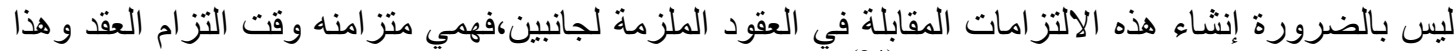

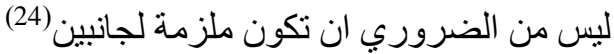

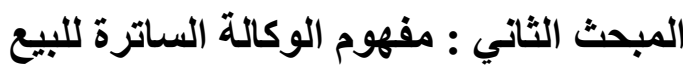

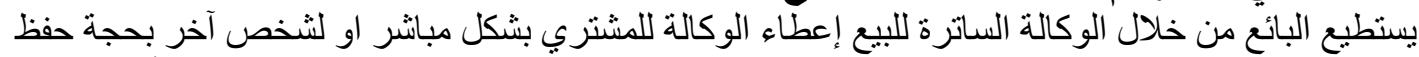

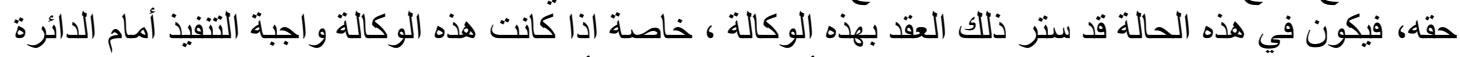

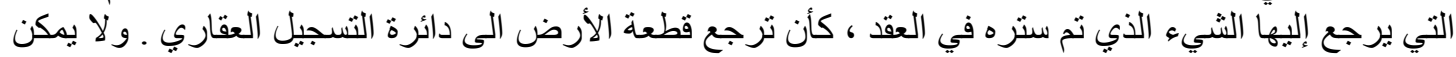

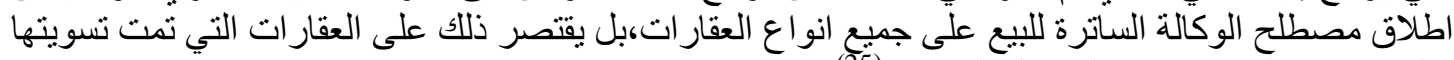

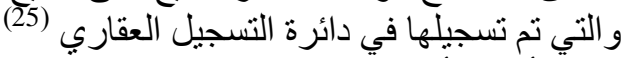

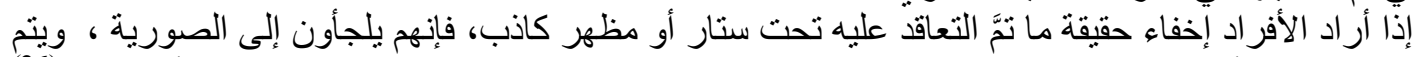

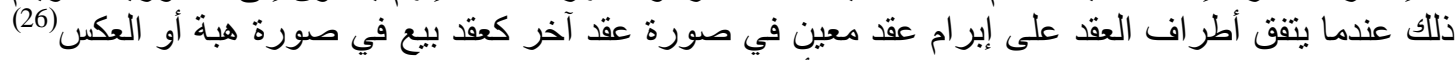

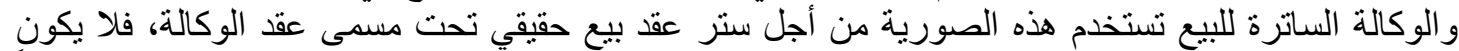

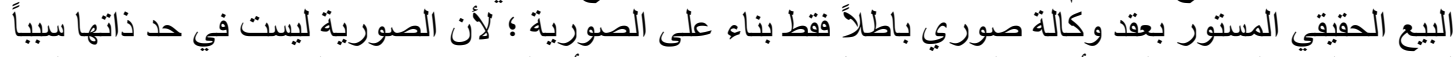

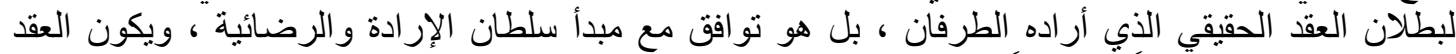

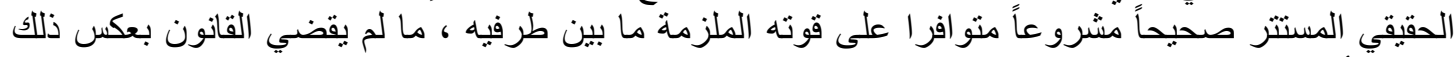

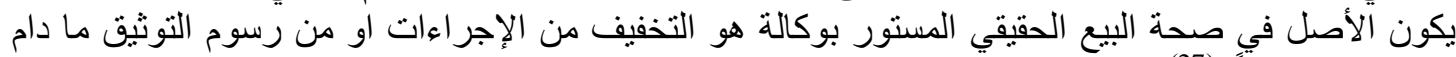

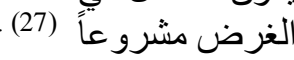

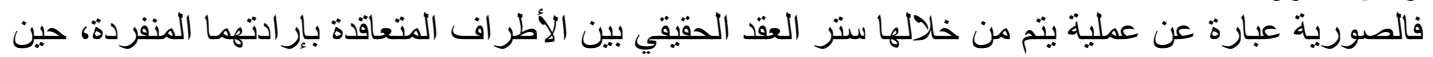

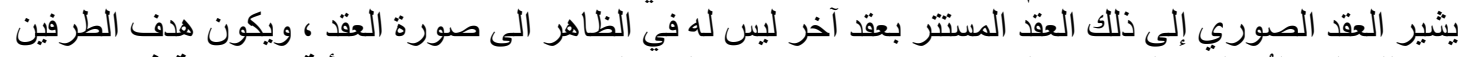

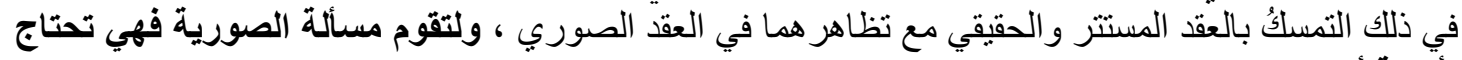

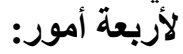

(19) موريس نخلة . الكامل في شرح القانون المدني :دراسة مقارنة .ج5. بيروت : منشورات الحلبي الحقوقية ، 2010م ص10

(20) قدري عبد الفتاح الثهاوي ـ أحكام عقد الوكالة في التشريع المصري و المقارن ـ الاسكندرية : منشأة المعارف ،

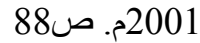

(21) عدنان ابراهيم السرحان. شرح القانون المدني العقود المسماة المقاولة ـالوكالة_الكفالة، ط1 ، مرجع سابق.

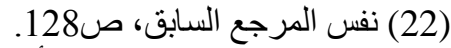

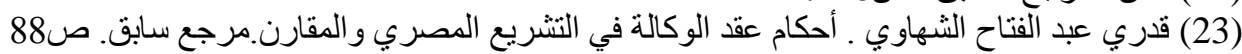

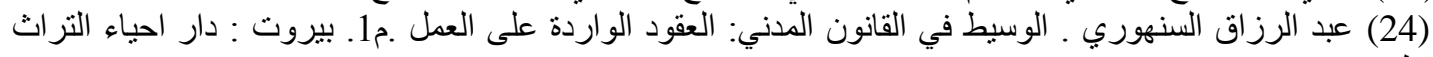

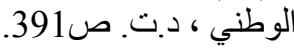

(25) حيدر سعيد جبر ـ الوكالة الغير قابلة للعزل و انقضاء اجلها ـ ـ رسالة ماجستير مقدمة الى كلية الحقوق جامعة الثرق

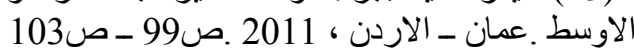

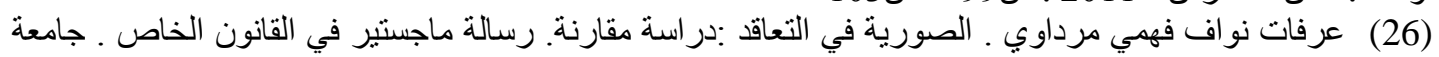

النجاح الوطنية . نابلس - فلسطين ، 2010 2010 .

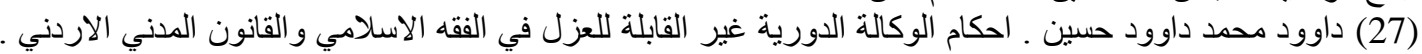

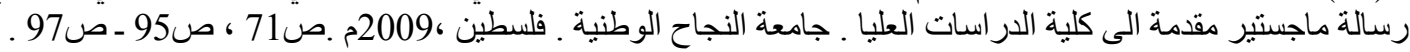


المجلة اللدولية اللملوم الأسانية والإجتاعياة

International Journal of Humanities and Social Sciences

website:www.ijohss.com

Email:editor@ijohss.com

أغسطس 2020

العدد (14)

ISSN: $2415-4822$

Volume (14) August 2020

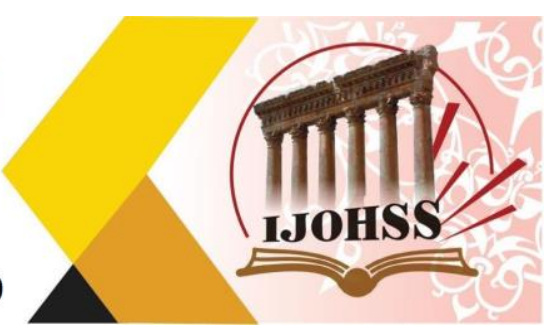

- - أن يكون هناك عقدين : إذ يتمثل العقد الأول في (العقد الحقيقي) باتفاق الأطر اف المتعاقدة ، بينما ينمثل العقد الاخر في (العقد الصوري).

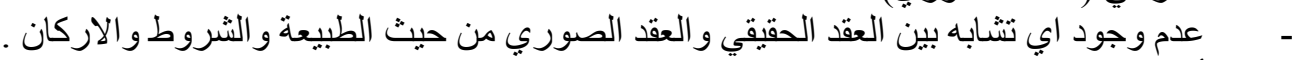

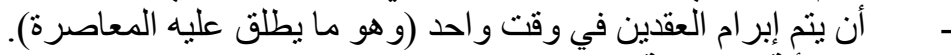

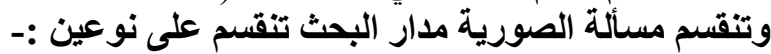
النوع الأول : الصورية المطلقة والتي تؤدي اللى إيجاد عقد ليس له أساس ، وهو الهو عقد وهمي يهدف الى التخلص من مجموعة من الالتز امات.

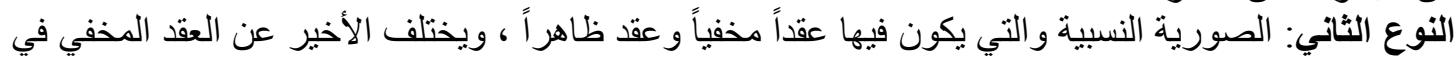

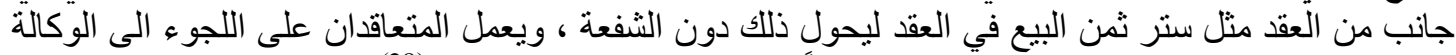

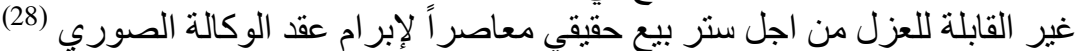

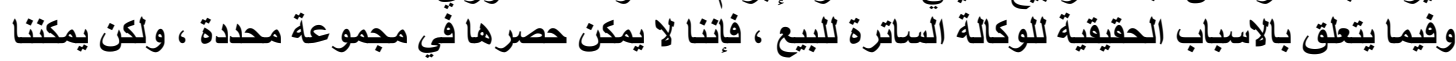
توضيح اهم الاسباب التي تعمل على تنظيمها:

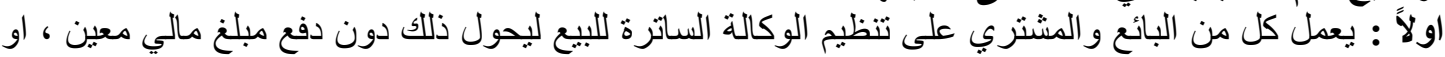

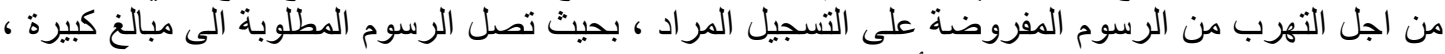

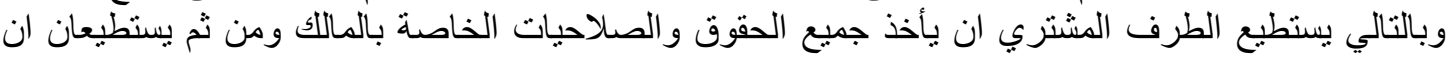

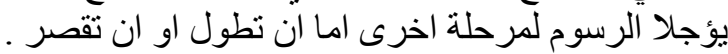

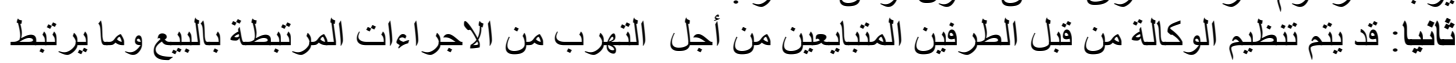

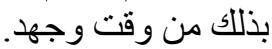

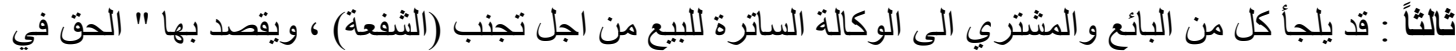

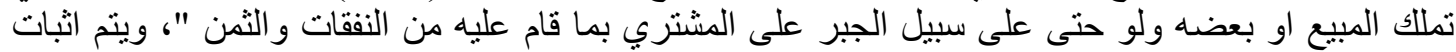

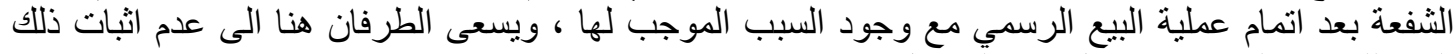

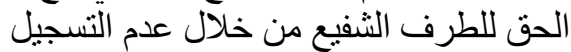

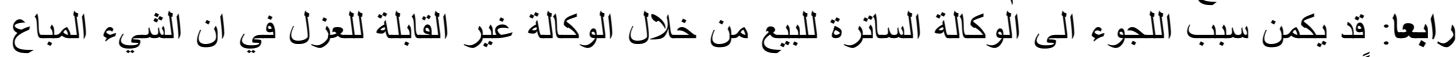

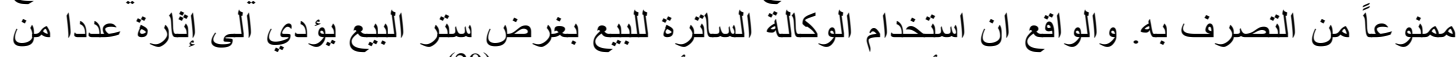

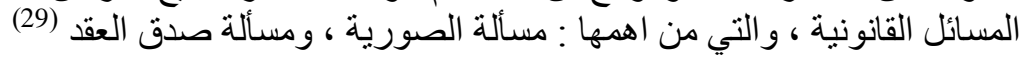

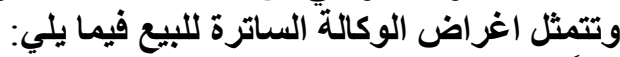

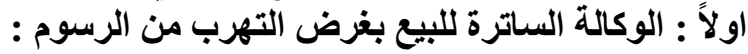

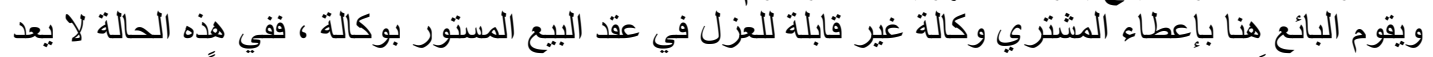

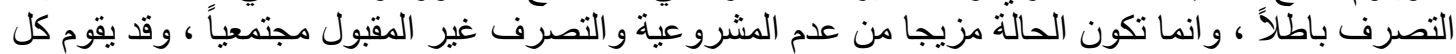

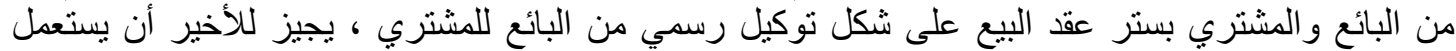

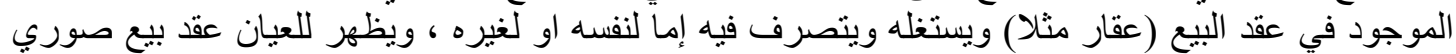

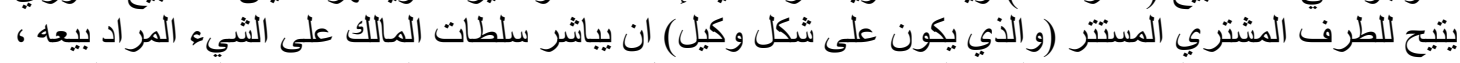

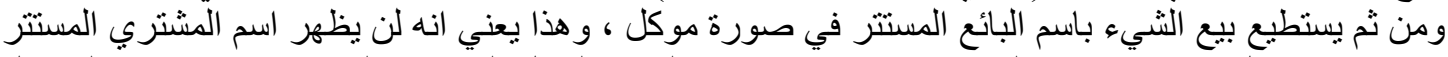

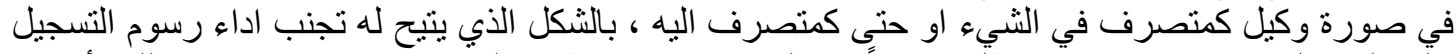

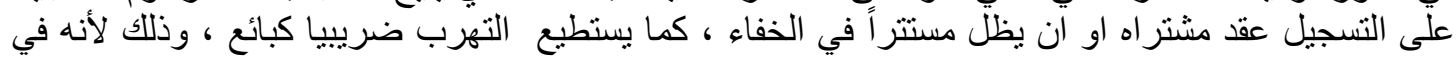

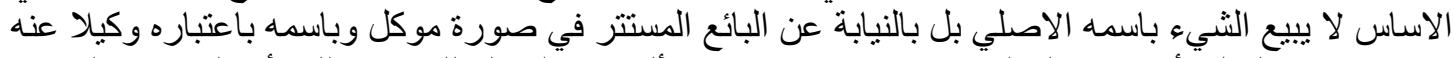

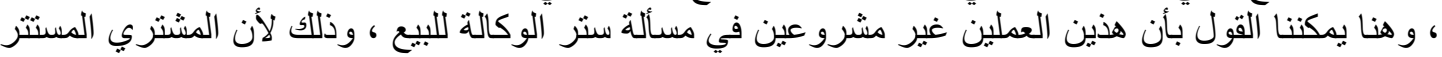

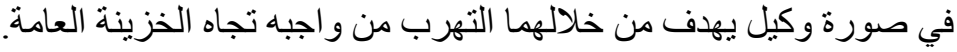


المجلة الحولية اللملوم الآسانية والإمتماعية

International Journal of Humanities and Social Sciences

website:www.ijohss.com

Email:editor@ijohss.com

ISSN: $2415-4822$

العدد (14) 2020 (14) August 2020
Volume (14)

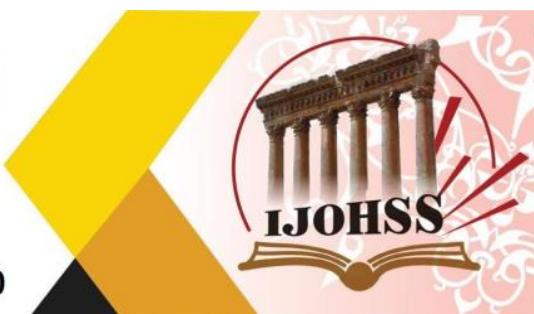

ثانياً : الوكالة الساترة للبيع بغرض عقد التصرف ممنوع التصرف فيه:

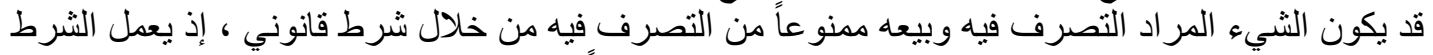

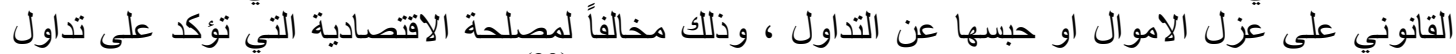

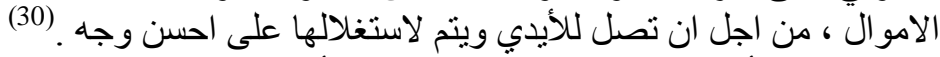

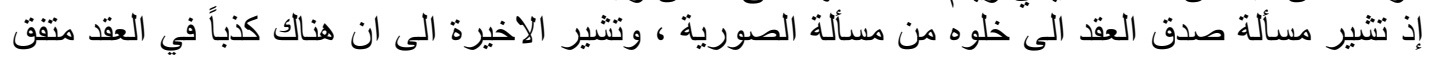

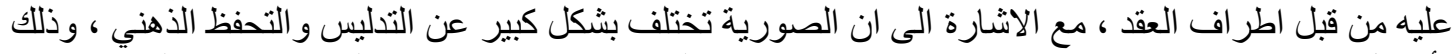

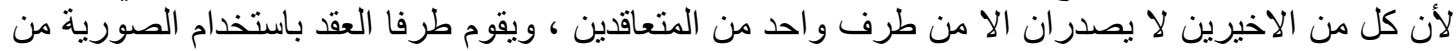

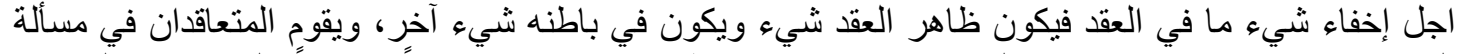

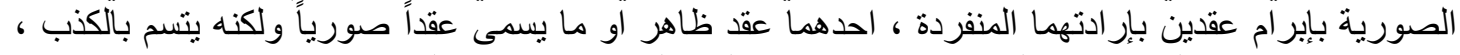

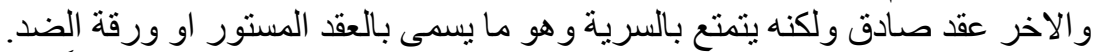

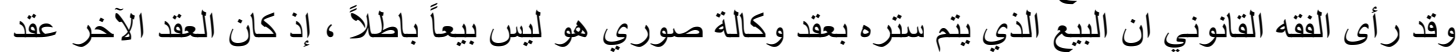

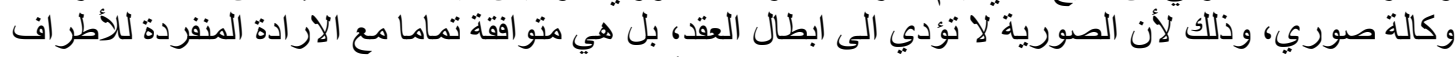

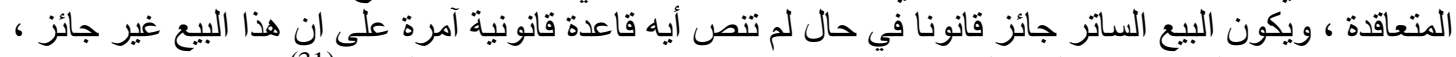

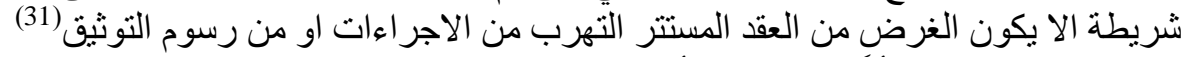

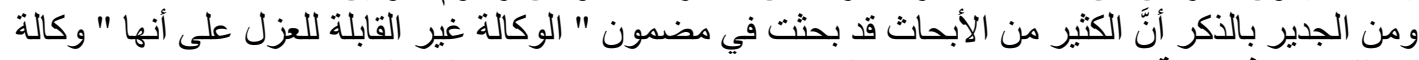

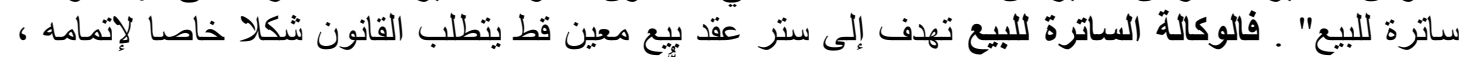

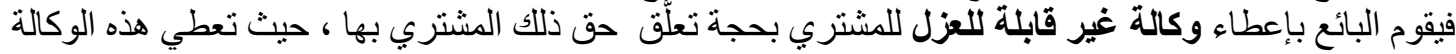

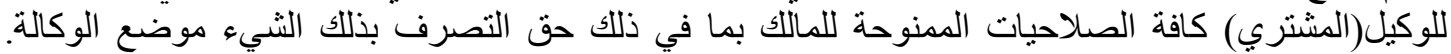

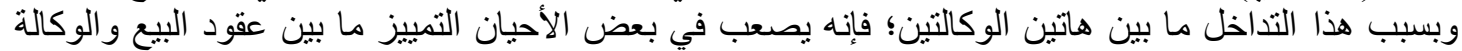

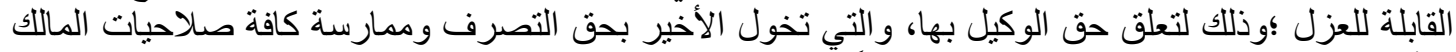

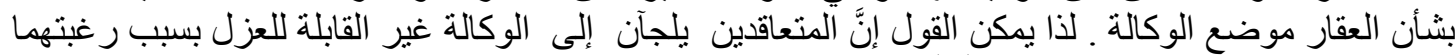

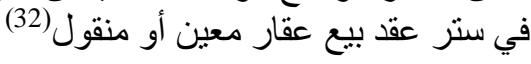

المبحث الثالث: موقف القانون العراقي والقوانين المقارنة من الوكالة الساترة للبيع

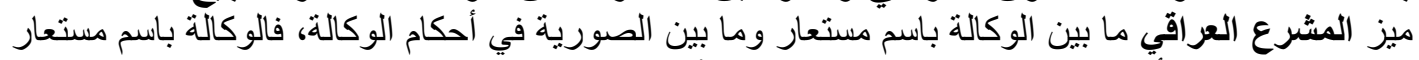

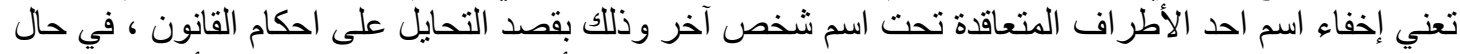

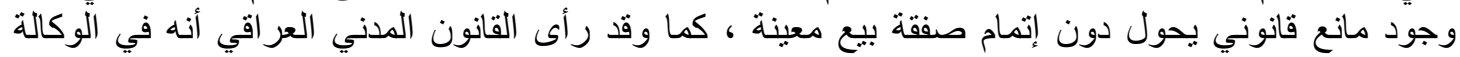

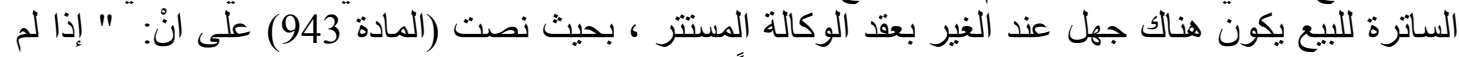

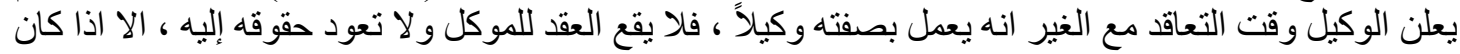

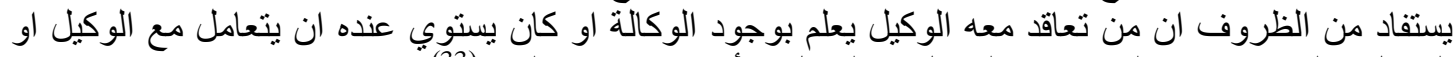

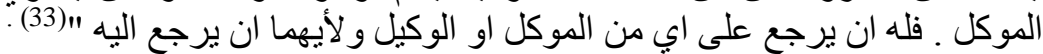

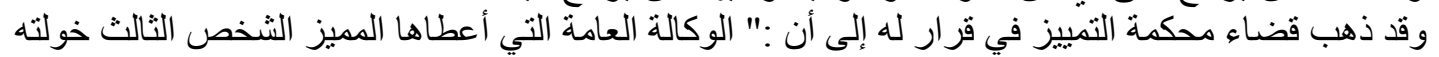

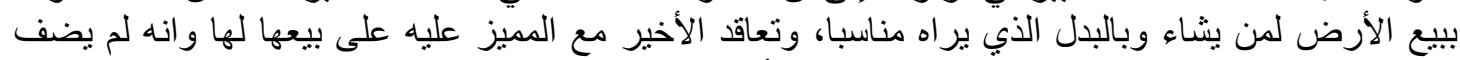

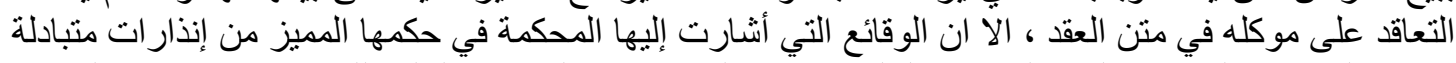

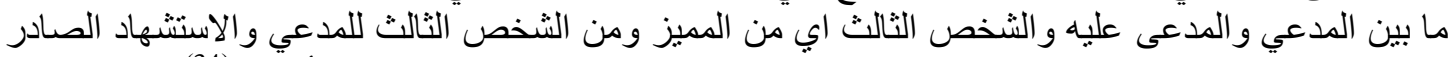
من دائرة الطابو ، إضافة لعقد الوكالة من المدعي عليه للثخص الثي الثالث المخول في بيع الأرض لئ (34).

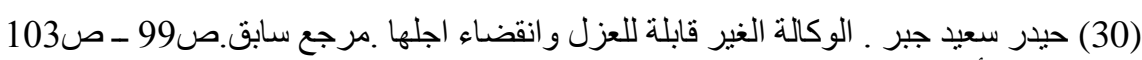

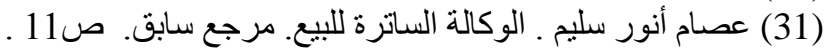

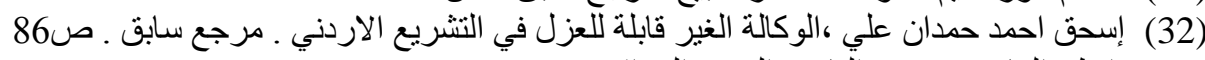

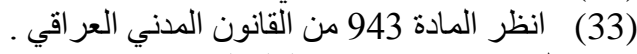

(34) القرار رقم921 / مدنية ثانية / 1974 في 22 / 1 / 1975 منشور في مجلة الاحكام العدلية - ع1 ، السنة السادسة (100، 
المجلة الحولية اللعلوم الآنسانية والإمتماعية

International Journal of Humanities and Social Sciences

website:www.ijohss.com

Email:editor@ijohss.com

ISSN: $2415-4822$

العدد (14) أغسطس 2020

Volume (14) August 2020

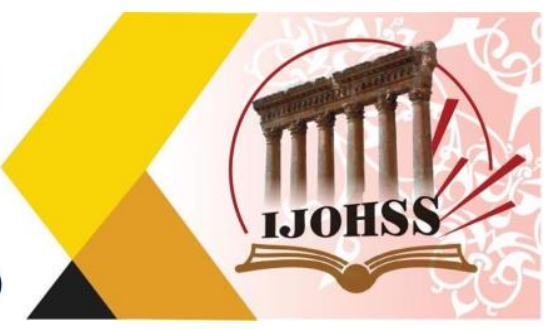

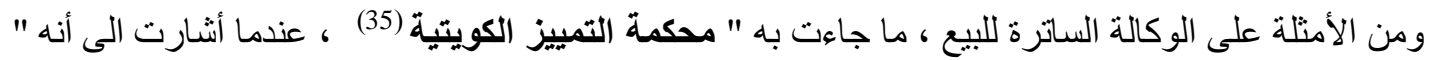

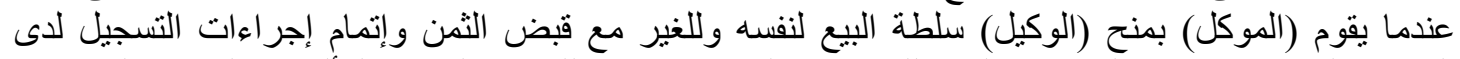

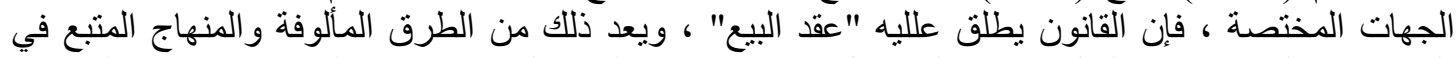

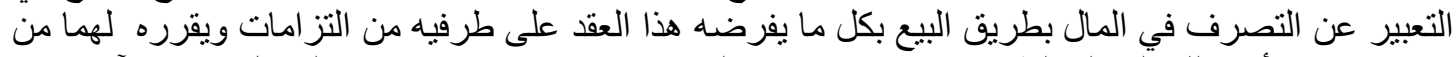

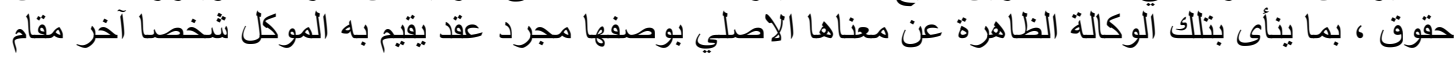

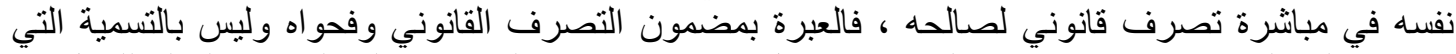

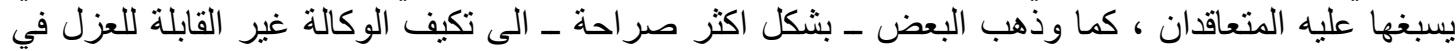

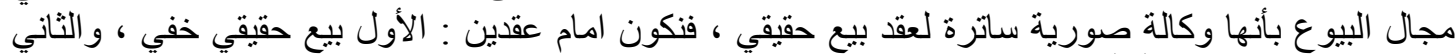
عقد وكالة زائف ظاهر (36) عانيان

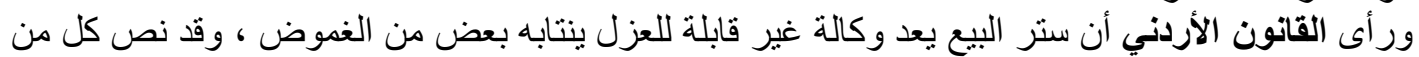

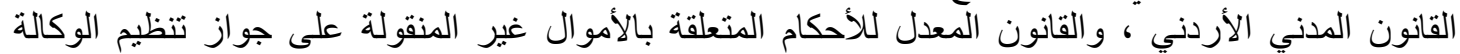

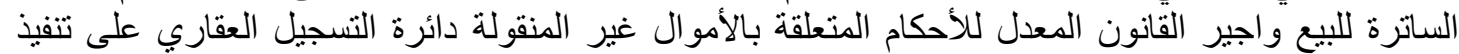

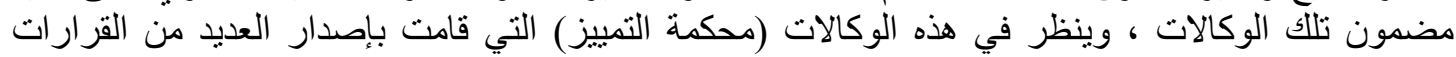

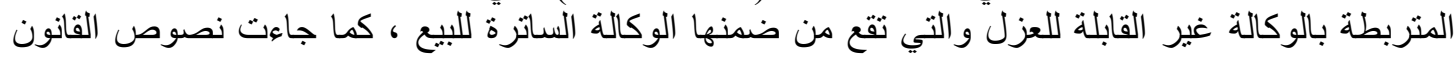

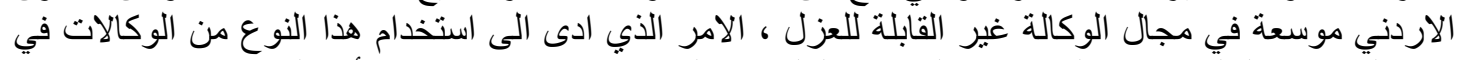

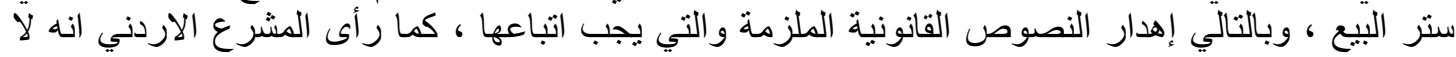

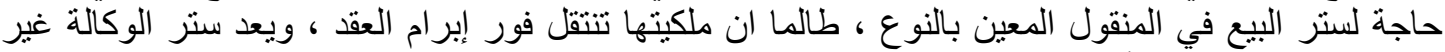

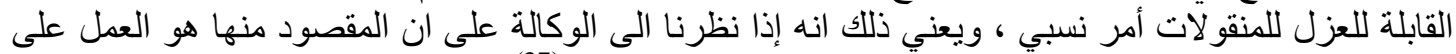

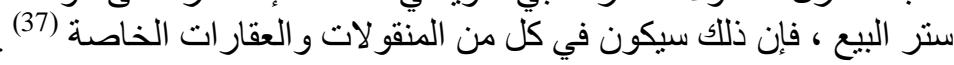

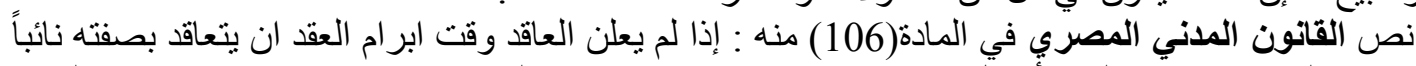

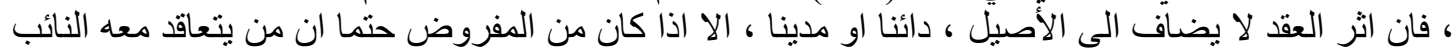

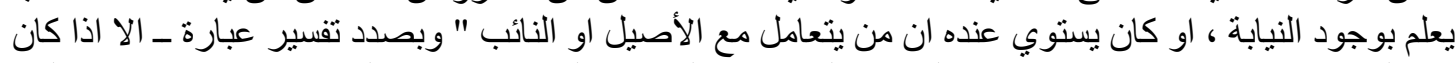

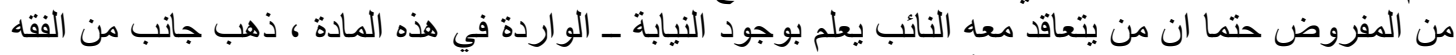

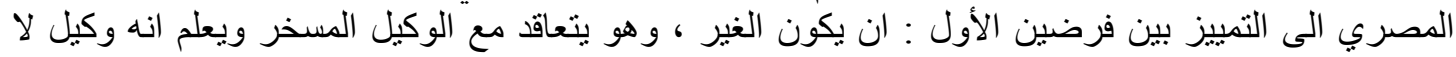

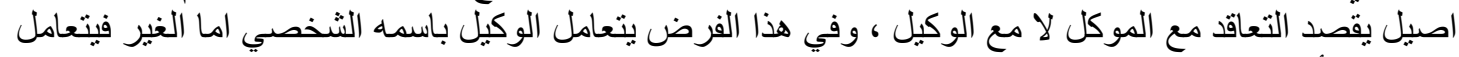

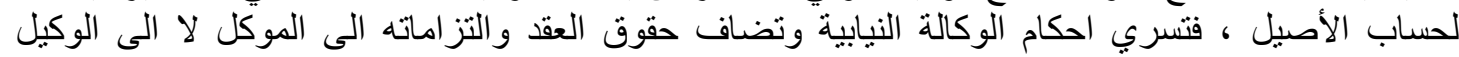

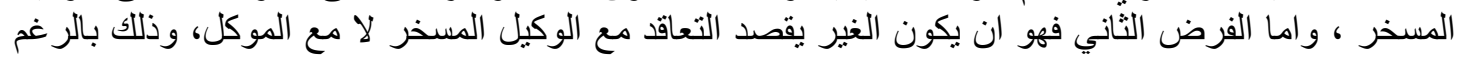

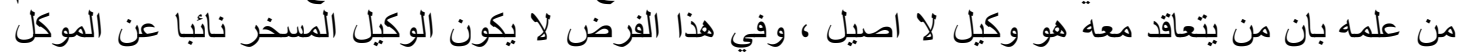

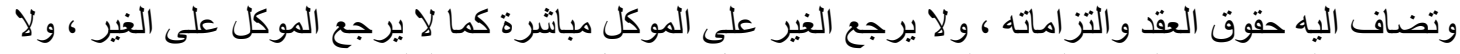

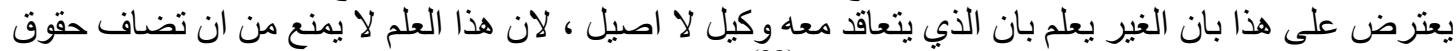

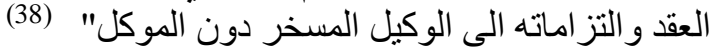

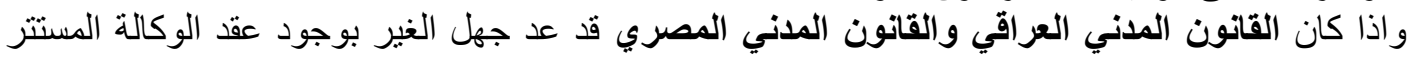

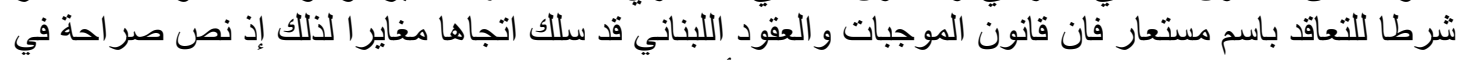

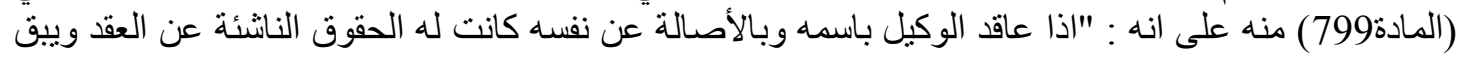

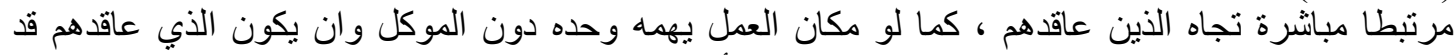

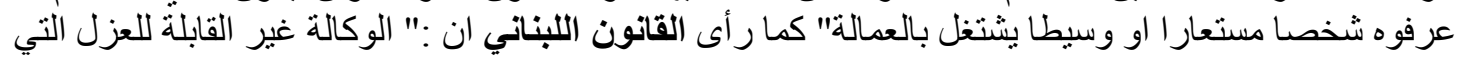

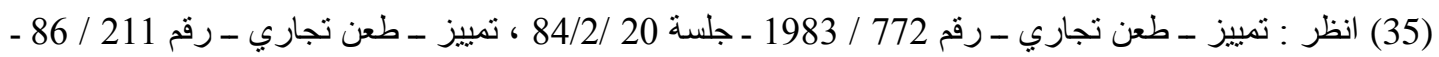

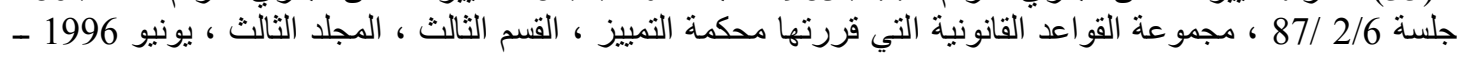

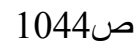

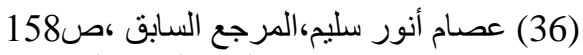

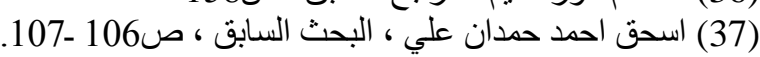

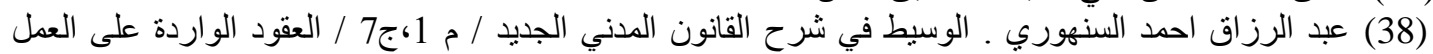

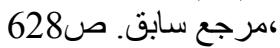


المجلة الحولية اللعلور الأسانية والإمتماعية

International Journal of Humanities and Social Sciences

website:www.ijohss.com

Email:editor@ijohss.com

ISSN: $2415-4822$

العدد (14) أغسطس 2020

Volume (14) August 2020

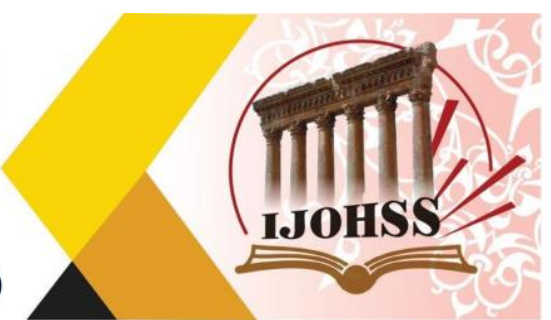

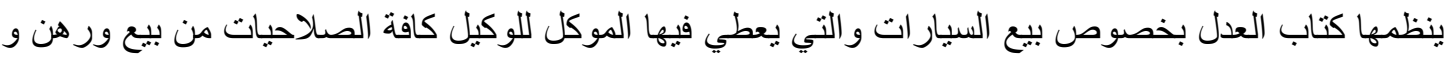

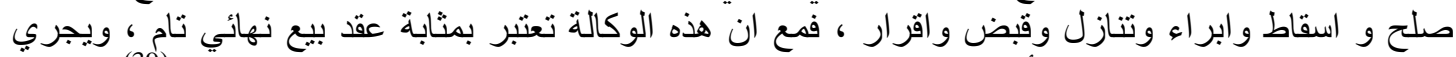

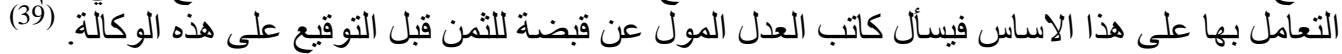

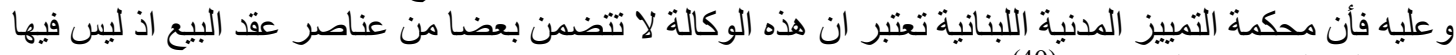

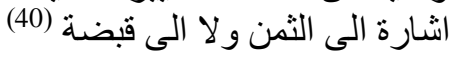

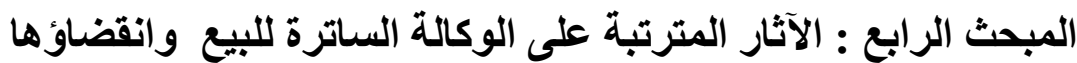

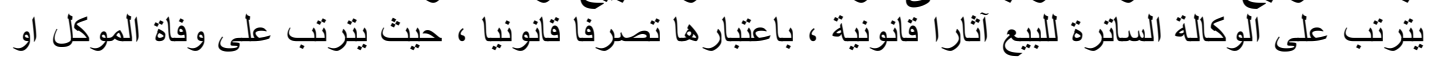

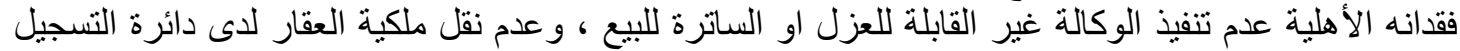

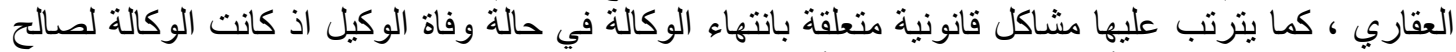

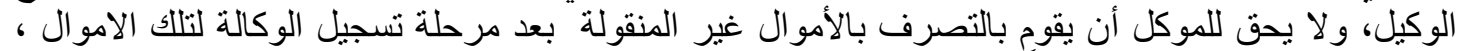

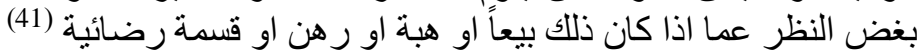

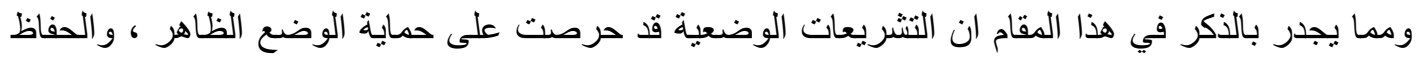

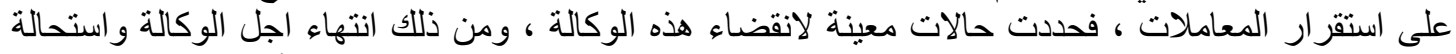

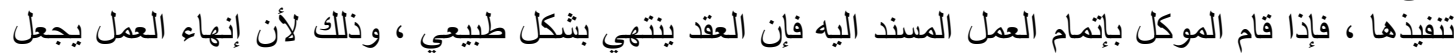

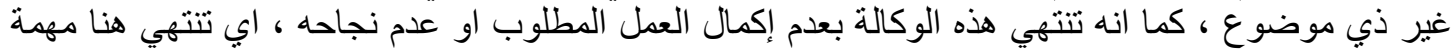

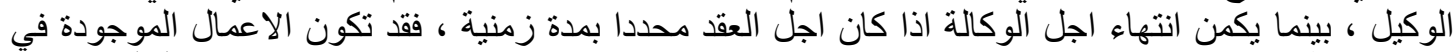

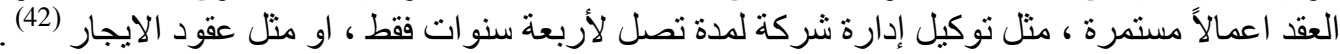

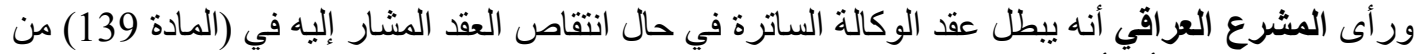

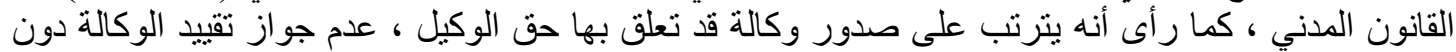

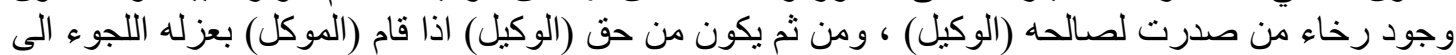

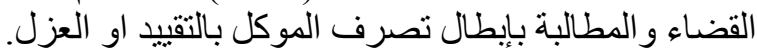

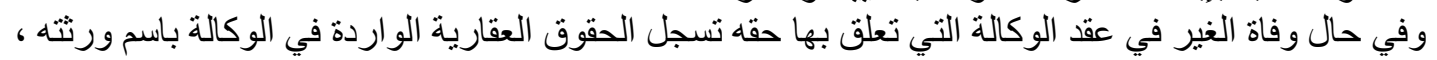

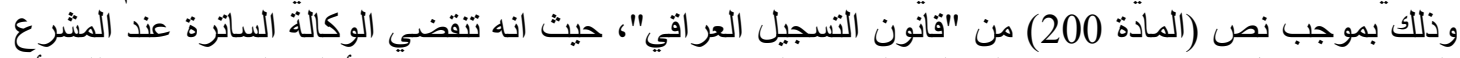

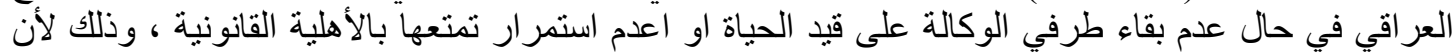

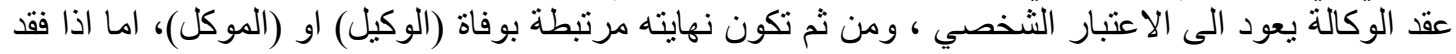

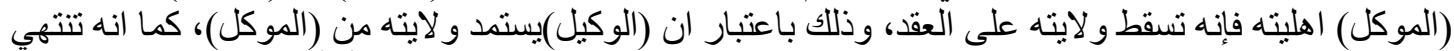

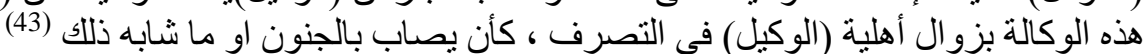

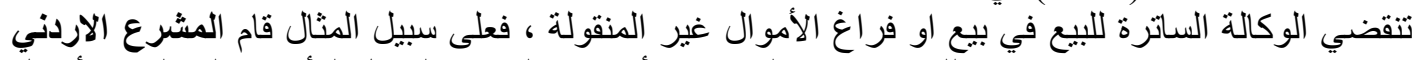

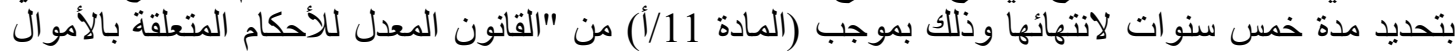

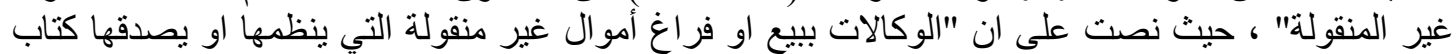

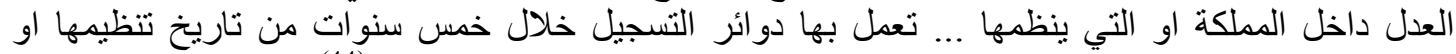

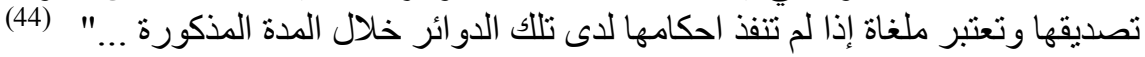

(39) موريس نخلة ، قانون الموجبات والعقود اللبناني الصادر في آذار 1932 ، منشورات الحلبي الحقوقية ، بيروت (1994 1994

(40) علي فارس ، سلطات وموجبات الوكيل و انتهاء وكالته في القانون المقارنة ، منشورات الحلبي الحقوقية ، بيروت

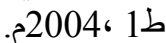

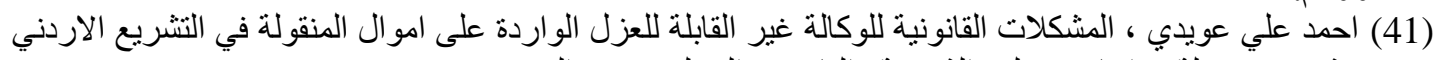

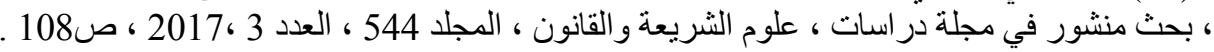

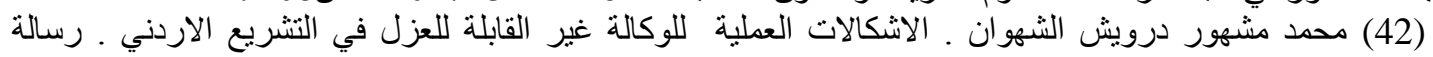

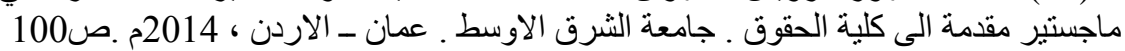

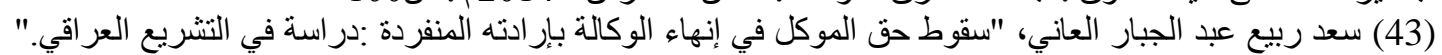

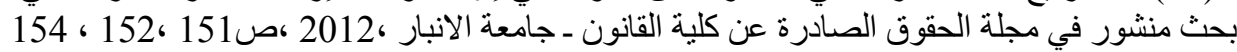
(44) قانون معدل للأحكام المتعلقة بالامو ال غير المنقولة رقم(51) لعام 1958 ، و المعدل بآخر قانون رقم 2009/18م. 
المجلة الحولية اللملوم الآسانية والإمتماعية

International Journal of Humanities and Social Sciences

website:www.ijohss.com

Email:editor@ijohss.com

ISSN: $2415-4822$
العدد (14) أغسطس 2020

Volume (14) August 2020

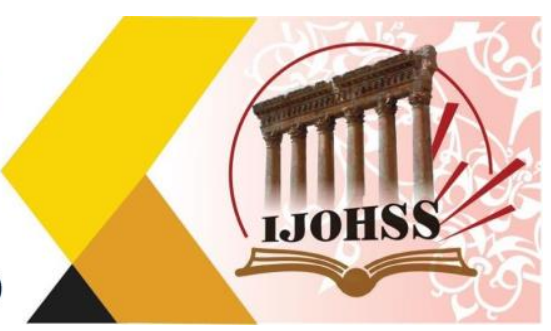

الخاتمة ( النتائج والتوصيات)

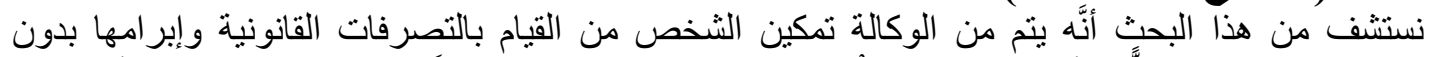

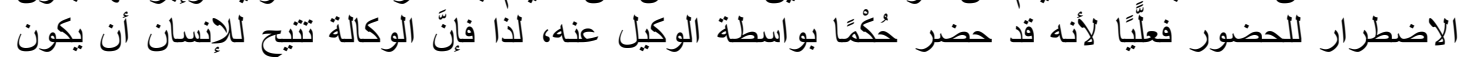

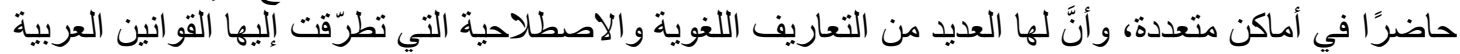

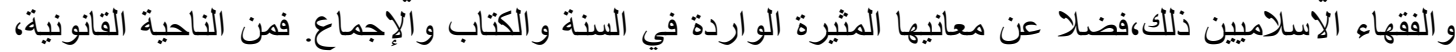

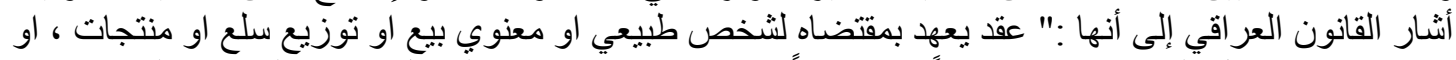

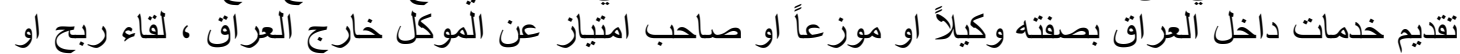

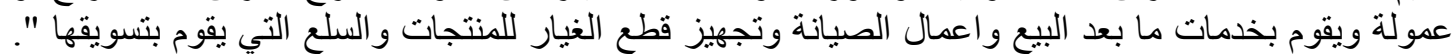

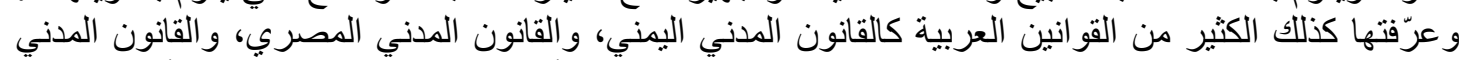

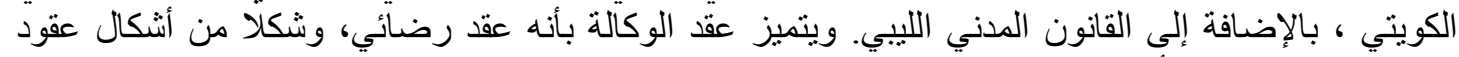

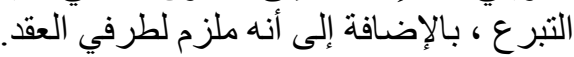

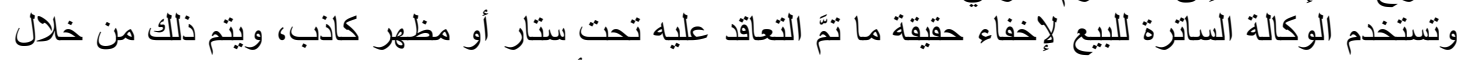

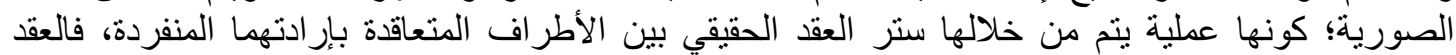

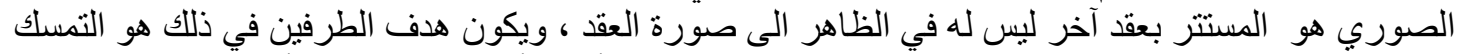

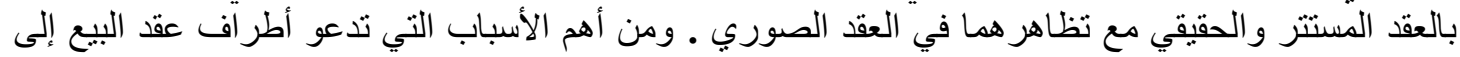

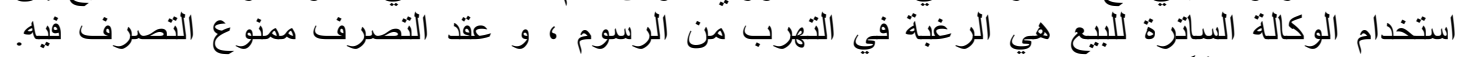

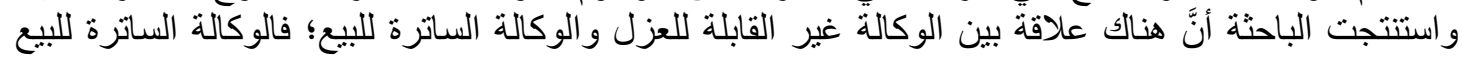

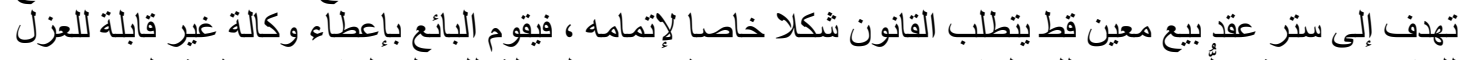

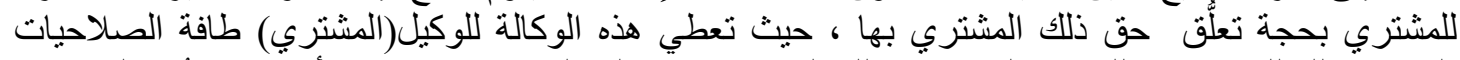

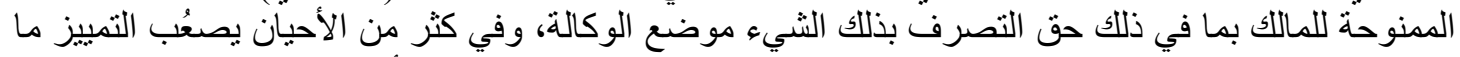

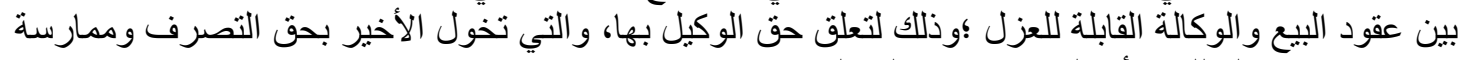

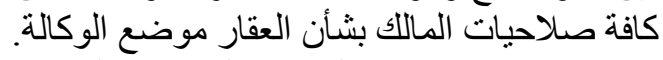

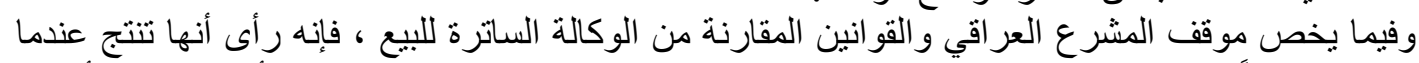

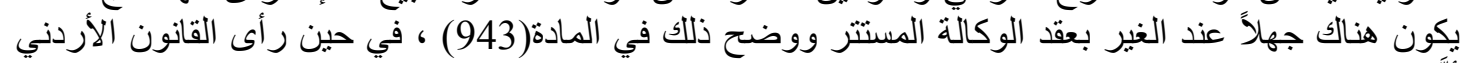

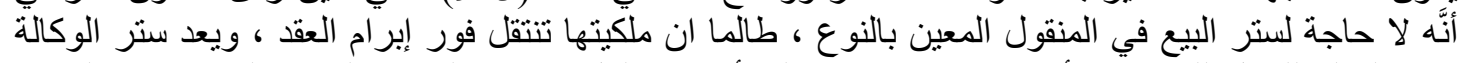

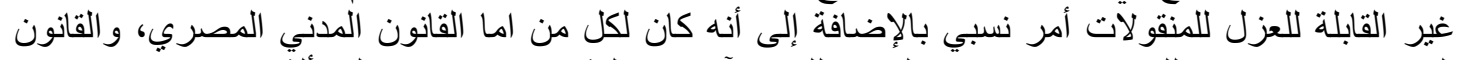

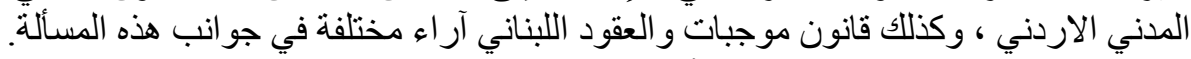

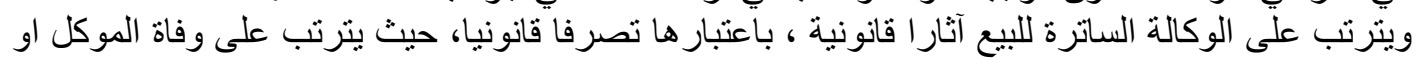

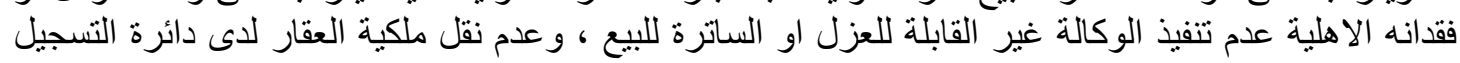

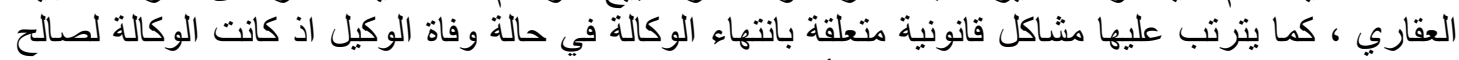

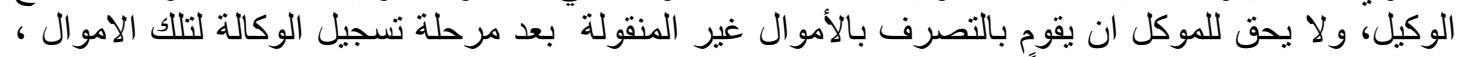

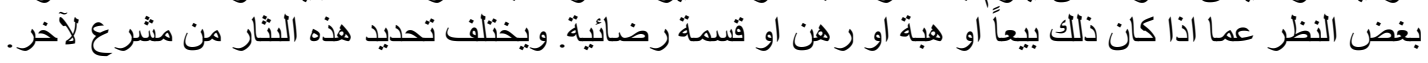

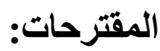

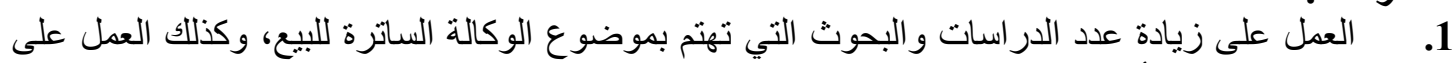

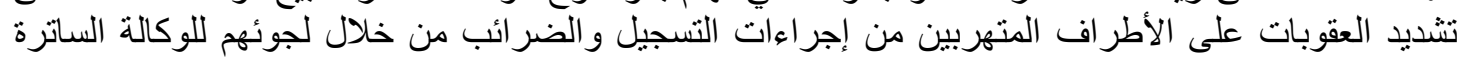

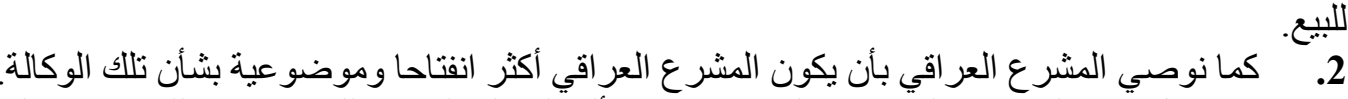

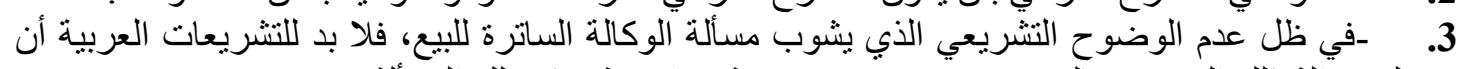

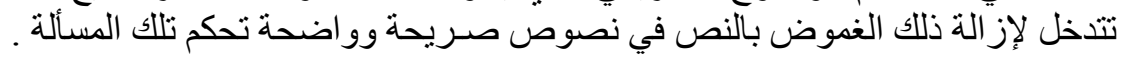




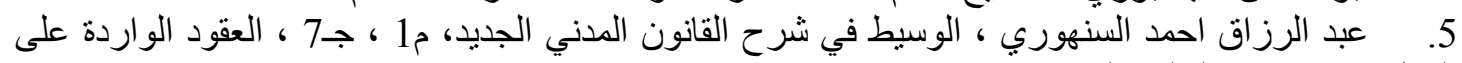

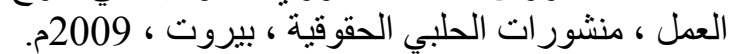
6. عبد الرزاق السنهوري ـ الوسيط في القانون الددني: العقود الواردة على العطل .م1. بيروت : دار احياء

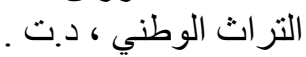
7.

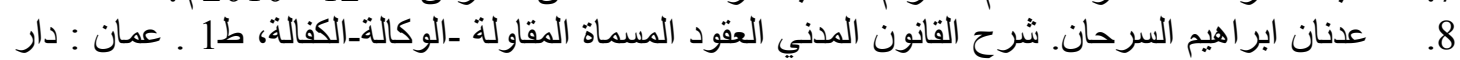

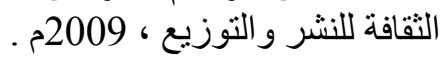
9. عرفات نوافت فهمي مرداوي ـ الصورية في التعاقد :دراسة مقارنة. رسالة ماجستير في القانون الخاص .

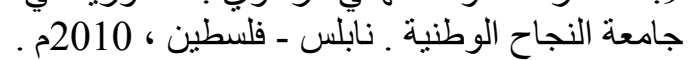

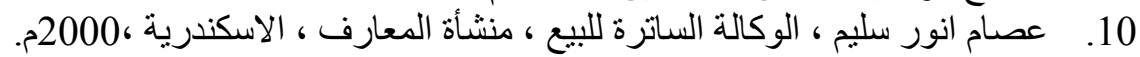

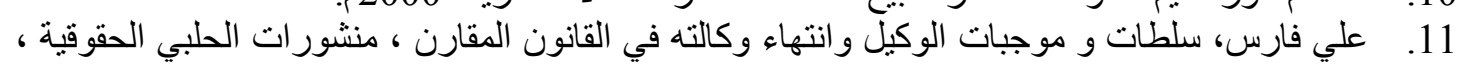

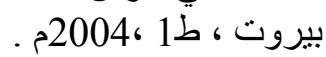
12. قلقري عبد الفتاح الشهاوي ـ أحكام عقد الوكالة في النتريع الكصري والمقارن ـ الاسكندرية : منشأة

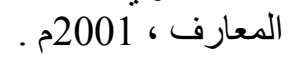
13. محمد رضا عبد الجبار العاني ـ الوكالة في الثريعة والقانون ـ ط1 ـ بيروت : دار الكتب العلمية ، 2007 14. موريس نظلة ـ الكامل في شرح القانون الدني :در اسة مقارنة .ج5. بيرون : منشور ات الحلبي الحقوقية ، 2010م. 15. موريس نخلة ، قانون الموجبات والعقود اللبناني الصادر في آذار 1932 ، منشورات الحلبي ، بيروت

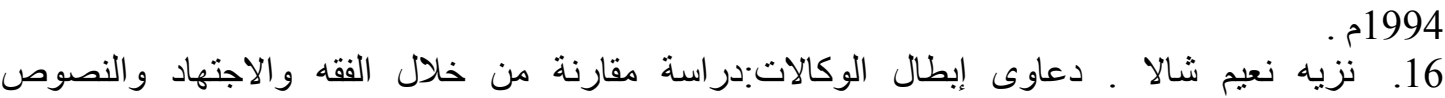
القانونية.ط1. بيروت : منشورات الحلبي الحقوقية ، 2010م .

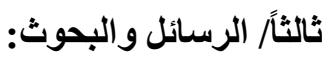

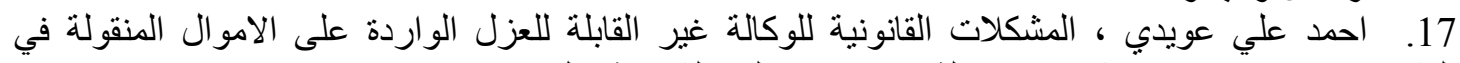

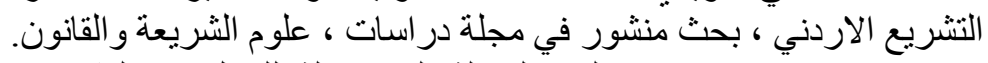

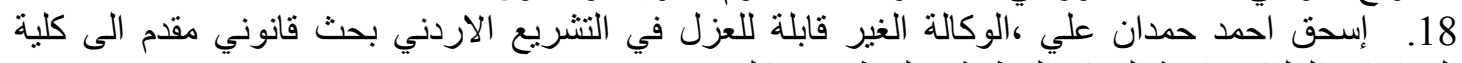

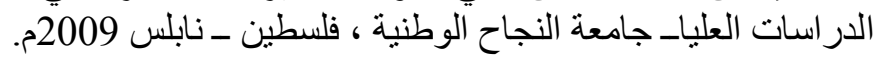

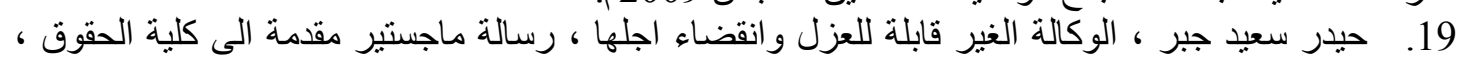

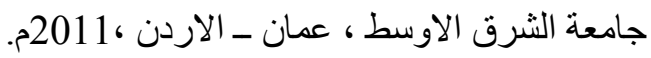

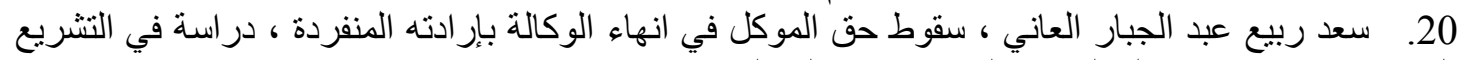

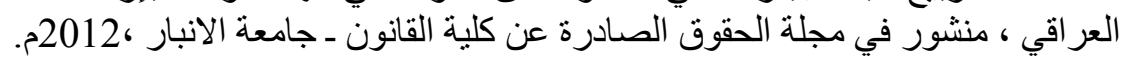

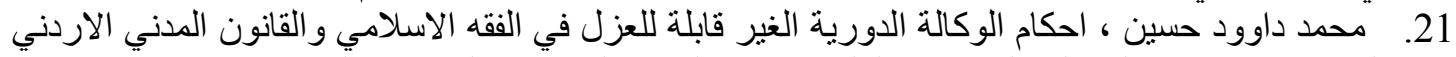

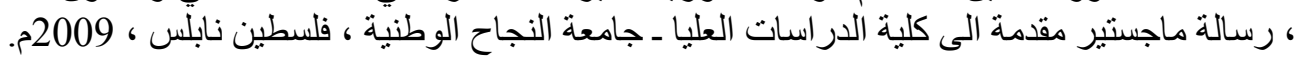




\section{المجلة الحولية اللملوم الآنسانية والإمتصاعية}

International Journal of Humanities and Social Sciences

website:www.ijohss.com

Email:editor@ijohss.com

أغسطس 2020

(14) (العدد)

ISSN: $2415-4822$

Volume (14) August 2020

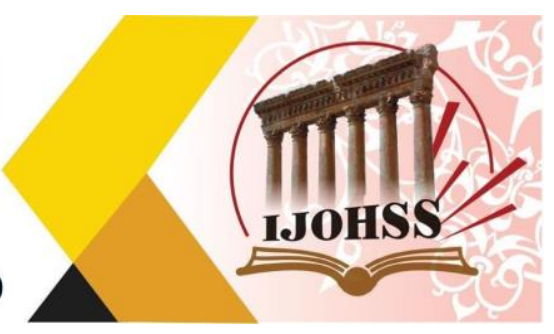

22. محد مشهور درويش الثهوان ، الاشكالات العملية للوكالة غير القابلة للعزل في التشريع الاردني ، الإني

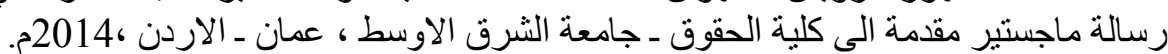

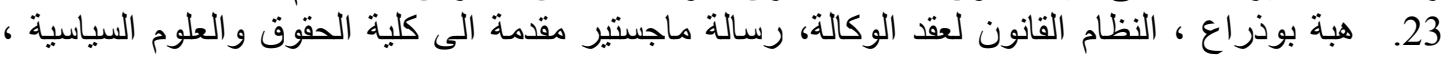

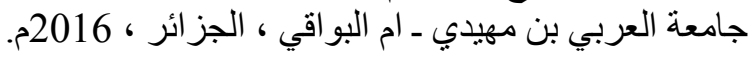

$$
\text { رابعاً/ القوانين والدوريات }
$$

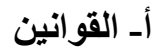

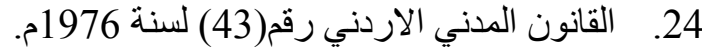

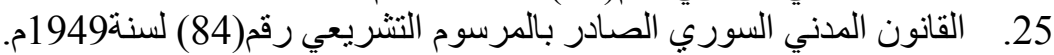

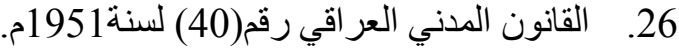

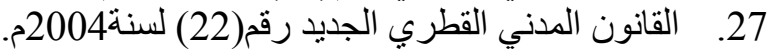

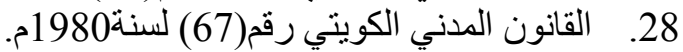

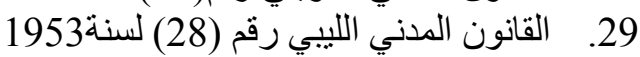

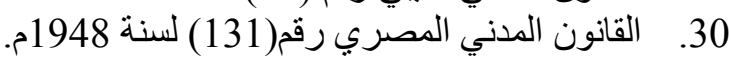

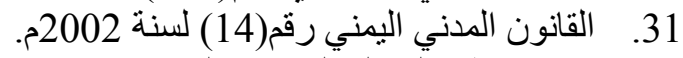

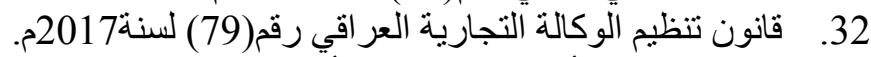

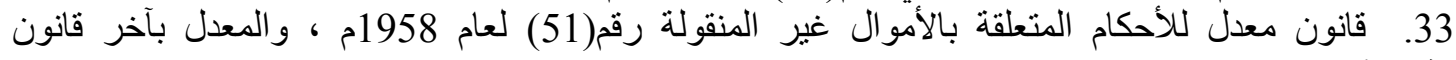

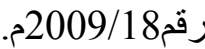

34. مجموعة القو اعد القانونية التي قررتها محكمة التمييز ، القسم الثالث ، المجلد الثالث، يونيو 1996م.

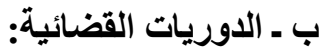

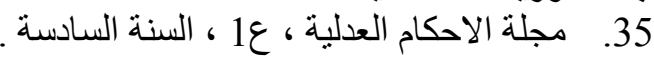

36. مجمو عة القو اعد القانونية التي قررتها محكمة التمبيز ، القسم الثالث ، المجلد الثالث ، يونيو 1996م. 


\section{References}

First / Islamic references:

1. The Holy Quran.

2. Abu Al-Hassan Al-Nisaboori, Sahih Muslim, Al-Mukhtar Foundation, Cairo, 1st edition, $2005 \mathrm{AD}$.

\section{Second / law books:}

3. Ibn Manzoor. Tongue of the Arabs. 3 C. 15. Beirut: Dar Sader Printing and Publishing, 2004.

4. Abu Al-Hassan Al-Nisaboori. Sahih Muslim, 1st edition. Cairo: Al-Mukhtar Foundation, 2005.

5. Abdul-Razzaq Ahmad Al-Sanhouri, Mediator in Explaining the New Civil Law, M1, Part 7, Contracts on Work, Al-Halabi Human Rights Publications, Beirut, 2009 AD.

6. Abdul Razzaq Al-Sanhouri. The mediator in the civil law: contracts received for work m. 1. Beirut: House of National Heritage Revival.

7. Abdel-Qader Muhammad Al-Far, Provisions of Commitment, Library of Culture House, Amman - Jordan, 12th, 2010AD.

8. Adnan Ibrahim Al-Sarhan. Civil Law Explanation of Contracts Named ContractWakala-Sponsorship, 1st Edition. Amman: House of Culture for Publishing and Distribution, 2009.

9. Arafat Nawaf Fahmy Mardawi. Moot in contracting: a comparative study. Master Thesis in Private Law. An-Najah National University . Nablus - Palestine, 2010. 10. Essam Anwar Selim, the cover agency for sale, Monshaat El Maarif, Alexandria, 2000

11. Ali Fares, The powers and obligations of the agent and the end of his agency in the comparative law, Al-Halabi Human Rights Publications, Beirut, 1st edition, 2004 $\mathrm{AD}$.

12. Qadri Abdul-Fattah Al-Shahawi. The provisions of the agency contract in the Egyptian and comparative legislation. Alexandria: Maarif facility, 2001.

13. Mohamed Reda Abdel-Jabbar Al-Ani. Agency in Sharia and Law. I 1. Beirut: Scientific Books House, 2007.

14. Maurice Nakhle. The Complete Explanation of Civil Law: A Comparative Study. 5. Byron: Al-Halabi Human Rights Publications, 2010.

15. Maurice Nakhleh, Lebanese Obligations and Contracts Law promulgated in March 1932, Al-Halabi Publications, Beirut 1994.

16. Nazih Naeem Shala. Lawsuits for nullifying agencies: a comparative study through jurisprudence, ijtihad and legal texts. I 1. Beirut: Al-Halabi Human Rights Publications, 2010.

\section{Third / Theses and Research:}

17. Ahmed Ali Awaidi, The Legal Problems of the Non-Isolated Agency Received on the Funds Transferred in Jordanian Legislation, Research published in the Journal of Studies, Sharia and Law Sciences. 
18. Ishaq Ahmad Hamdan Ali, the non-segregated agency in Jordanian legislation, legal research submitted to the College of Graduate Studies, An-Najah National University, Palestine - Nablus 2009.

19- Haider Saeed Jabr, the agency that is not subject to removal and expiration, a master's thesis submitted to the Faculty of Law, Middle East University, Amman Jordan, 2011.

20. Saad Rabie Abdul-Jabbar Al-Ani, The Right of the Principal to Terminate the Agency by His Individual Will Fall, Study in Iraqi Legislation, published in the Law Journal issued by the College of Law - Anbar University, 2012 AD.

21. Muhammad Dawood Hussein, The Provisions of the Periodical Unimmissible Agency in Islamic Jurisprudence and Jordanian Civil Law, Master Thesis submitted to the College of Graduate Studies - An-Najah National University, Palestine, Nablus, 2009

22. Muhammad Mashhour Darwish Al-Shahwan, Practical Problems of the NonIsolated Agency in Jordanian Legislation, Master Thesis submitted to the Faculty of Law - Middle East University, Amman - Jordan, 2014 AD.

23. Heba Boudra'a, The Legal System of the Agency Contract, Master Thesis submitted to the Faculty of Law and Political Science, Arab Bin Mahidi University Umm Al-Baqi, Algeria, 2016 AD.

\section{Fourth / laws and periodicals}

\section{A- Laws}

24. Jordanian Civil Law No. (43) of 1976.

25. The Syrian Civil Law promulgated by Legislative Decree No. 84 of 1949.

26. Iraqi Civil Law No. (40) of 1951AD.

27. New Qatari Civil Law No. (22) of 2004.

28. Kuwaiti Civil Law No. (67) of 1980.

29. Libyan Civil Law No. (28) of 1953

30. Egyptian Civil Law No. (131) for the year 1948 AD.

31. Yemeni Civil Law No. (14) of 2002.

32. Iraqi Commercial Agency Regulation Law No. (79) of 2017.

33. Law amending the provisions related to immovable property No. (51) of 1958 AD, and amending it at the end of Law No. 18/2009.

34. The set of legal rules decided by the Court of Cassation, Section III, Volume III, June 1996.

\section{B- Judicial periodicals:}

35. The Judicial Judgments Magazine, No. 1, sixth year.

36. The set of legal rules decided by the Court of Cassation, Section III, Volume III, June 1996. 